\title{
Prior activation of inositol 1,4,5-trisphosphate receptors suppresses the subsequent induction of long-term potentiation in hippocampal CA1 neurons
}

\author{
Satoshi Fujii, ${ }^{1,2}$ Yoshihiko Yamazaki, ${ }^{1}$ Jun-Ichi Goto, ${ }^{1,2}$ Hiroki Fujiwara, ${ }^{1}$ \\ and Katsuhiko Mikoshiba ${ }^{2}$ \\ ${ }^{1}$ Department of Physiology, Yamagata University School of Medicine, Yamagata 990-9585, Japan; ${ }^{2}$ Laboratory for Developmental \\ Neurobiology, Riken Brain Science Institute, Wako, Saitama 351-0198, Japan
}

\begin{abstract}
We investigated the role of inositol 1,4,5-trisphosphate receptors ( $\mathrm{IP}_{3} \mathrm{Rs}$ ) activated by preconditioning low-frequency afferent stimulation (LFS) in the subsequent induction of long-term potentiation (LTP) in CAl neurons in hippocampal slices from mature guinea pigs. Induction of LTP in the field excitatory postsynaptic potential or the population spike by the delivery of high-frequency stimulation (HFS, a tetanus of 100 pulses at $100 \mathrm{~Hz}$ ) to the Schaffer collateral-commissural pathway to CA1 neuron synapses was suppressed when group I metabotropic glutamate receptors (mGluRs) were activated prior to the delivery of HFS. LTP induction was also suppressed when CAl synapses were preconditioned 60 min before HFS by LFS of 1000 pulses at $1 \mathrm{~Hz}$ and this effect was inhibited when the test stimulation delivered at $0.05 \mathrm{~Hz}$ was either halted or applied in the presence of an antagonist of $\mathrm{N}$-methyl-D-aspartate receptors, group I mGluRs, or $\mathrm{IP}_{3} \mathrm{Rs}$ during a 20 -min period from 20 to 40 min after the end of LFS. Furthermore, blockade of group I mGluRs or $I_{3} R_{3}$ immediately before the delivery of HFS overcame the effects of the preconditioning LFS on LTP induction. These results suggest that, in CA1 neurons, after a preconditioning LFS, activation of group I mGluRs caused by the test stimulation results in $I P_{3} R s$ activation that leads to a failure of LTP induction.
\end{abstract}

Activity-dependent modification of synaptic efficacy is fundamental to the storage of information in the brain. Long-term potentiation (LTP) in the hippocampus is a long-lasting change in synaptic efficacy and is thought to play an important role in learning and memory (Bliss and Collingridge 1993). The highfrequency stimulation (HFS)-induced LTP at CA1 synapses is generally believed to be triggered by the influx, during HFS, of $\mathrm{Ca}^{2+}$ into the postsynaptic neuron through channels coupled to $\mathrm{N}$-methyl-D-aspartate glutamate receptors (NMDARs), and this increase in the intracellular $\mathrm{Ca}^{2+}$ concentration $\left(\left[\mathrm{Ca}^{2+}\right]_{\mathrm{i}}\right)$ activates $\mathrm{Ca}^{2+} /$ calmodulin-dependent protein kinase II (CaMKII) to phosphorylate the GluA1 subunit of the $\alpha$-amino-3-hydroxy-5-methyl-4-isoxazole propionic acid receptor (AMPAR) in postsynaptic neurons (Alford et al. 1993; Bliss and Collingridge 1993).

Activation of metabotropic glutamate receptors (mGluRs) can facilitate the HFS-induced LTP in CA1 neurons (Behnisch and Reymann 1993) and is, therefore, also believed to be a significant functional component of the cellular mechanisms of LTP formation in hippocampal CA1 neurons (Bashir et al. 1993). Stimulation of group I mGluRs on hippocampal neurons activates phospholipase $\mathrm{C}$, which hydrolyses the inositol lipid precursor in the postsynaptic plasma membrane into inositol 1,4,5-trisphosphate $\left(\mathrm{IP}_{3}\right)$ and diacylglycerol, the former opening $\mathrm{IP}_{3}$ receptor $\left(\mathrm{IP}_{3} \mathrm{R}\right)$ channels and the latter activating protein kinase $\mathrm{C}(\mathrm{PKC})$ (Ben-Ari et al. 1992; Nakanishi 1992). $\mathrm{IP}_{3} \mathrm{Rs}$ act as $\mathrm{IP}_{3}$-gated $\mathrm{Ca}^{2+}$ release channels in a variety of cells (Berridge 1993; Mikoshiba 1993).

The type $1 \mathrm{IP}_{3} \mathrm{R}\left(\mathrm{IP}_{3} \mathrm{R} 1\right)$ is the major $\mathrm{IP}_{3} \mathrm{R}$ family member in the central nervous system and is predominantly enriched in cerebellar Purkinje cells and hippocampal neurons (Furuichi et al.

Corresponding author: sfujii@med.id.yamagata-u.ac.jp Article is online at http://www.learnmem.org/cgi/doi/10.1101//m.041053.115.
1989; Nakanishi et al. 1991). Activation of $\mathrm{IP}_{3} \mathrm{Rs}$ during, or after, HFS is involved in the mechanism of LTP induction in hippocampal CA1 neurons (Yoshioka et al. 2010). We previously demonstrated that LTP induction in hippocampal CA1 neurons is facilitated in $\mathrm{IP}_{3}$ R1-lacking mice (Matsumoto et al., 1996) when CA1 synaptic inputs are stimulated by a brief tetanus of 10 pulses at $100 \mathrm{~Hz}$ (Fujii et al. 2000b) or when CA1 synapses are activated by a standard tetanus of 100 pulses at $100 \mathrm{~Hz}$ (Nagase et al. 2003). In addition, bath application of 2-aminoethoxydiphenyl borate (2-APB), an antagonist for both $\mathrm{IP}_{3} \mathrm{Rs}$ and store-operated calcium (SOC) channels (Maruyama et al. 1997; Iwasaki et al. 2001; Bootman et al. 2002; Peppiatt et al. 2003), or of $\alpha$-methyl4-carboxyphenylglycine (MCPG), a wide-spectrum mGluR antagonist (Pin and Duvoisin 1995), during brief HFS (10 or 15 pulses at $100 \mathrm{~Hz}$ ) significantly increases the magnitude of the LTP in hippocampal CA1 neurons (Taufiq et al. 2005). These results suggest that $\mathrm{IP}_{3} \mathrm{R} 1 \mathrm{~s}$ play an important role in inhibiting LTP induction in hippocampal CA1 neurons.

Induction of LTP or LTD can be regulated by previous lowfrequency synaptic activity at both CA1 synapses (Mocket et al. 2002; Young and Nguyen 2005, Fujii et al. 2010) and CA3 synapses (Yamazaki et al. 2012a). In our previous studies (Fujii et al. 1991, $1996,2000 a)$, we reported a type of synaptic plasticity in hippocampal CA1 neurons that we refer to as "LTP suppression," in which a train of low-frequency stimulation (LFS) given prior to the delivery of HFS (100 pulses at $100 \mathrm{~Hz})$ suppresses LTP induction. One of our studies on LTP suppression in hippocampal

(C) 2016 Fujii et al. This article is distributed exclusively by Cold Spring Harbor Laboratory Press for the first 12 months after the full-issue publication date (see http://learnmem.cshlp.org/site/misc/terms.xhtml). After 12 months, it is available under a Creative Commons License (Attribution-NonCommercial 4.0 International), as described at http://creativecommons.org/licenses/by$\mathrm{nc} / 4.0 /$. 
CA1 neurons (Fujii et al. 1996) showed a suppressive effect of a preconditioning LFS of 200 or 1000 pulses at $1 \mathrm{~Hz}$ on HFS-induced LTP in the field responses and that this suppressive effect was significantly reduced when the LFS at $1 \mathrm{~Hz}$ consisted of fewer pulses (80 pulses), when the time lag between LFS and HFS was shorter (20 min) or longer (100 min), or when LFS at a higher frequency $(5 \mathrm{~Hz})$ was used.

Bortolotto et al. (1994) reported that, in hippocampal CA1 neurons, stimulation of mGluRs has a preconditioning effect on the HFS-induced LTP and that this effect involves processes that are disrupted by LFS given prior to HFS, and suggested that this preconditioning effect of LFS involves protein dephosphorylation. Hulme et al. (2012) showed that delivery of two trains of priming HFS $(10,20,50$, or $100 \mathrm{~Hz}, 10$-min interval) to CA1 synaptic inputs reduces the level of LTP induced by a subsequent two trains of HFS $(100 \mathrm{~Hz}, 1$-sec trains with a 30 -sec interval) and that this effect is attenuated when the HFS are delivered in the presence of an $\mathrm{IP}_{3} \mathrm{R}$ inhibitor. In addition, we ourselves demonstrated that the suppression of LTP induction by a preconditioning LFS (1000 pulses at $1 \mathrm{~Hz}$ ) given 60 min before an HFS of 100 pulses at $100 \mathrm{~Hz}$ is attenuated in hippocampal CA1 neurons in $\mathrm{IP}_{3} \mathrm{R} 1-$ deficient mice (Fujii et al. 2000b). Recently, we showed that coactivation of NMDARs and $\mathrm{IP}_{3}$ Rs during a preconditioning LFS results in an increase in the postsynaptic $\left[\mathrm{Ca}^{2+}\right]_{\mathrm{i}}$ in hippocampal CA1 neurons and in the dephosphorylation of synaptic proteins, leading to suppression of subsequent LTP induction (Yamazaki et al. 2015). However, the detailed mechanisms of LTP suppression during the period after LFS in hippocampal CA1 neurons are still unknown. In the present study, we investigated the role of $\mathrm{IP}_{3} \mathrm{Rs}$ in this suppression of LTP induction in the hippocampal CA1 region of mature guinea pigs and used a pharmacological approach to study the role of NMDARs, group I mGluRs, and $\mathrm{IP}_{3} \mathrm{Rs}$, activated after LFS, in the subsequent HFS-mediated induction of LTP in CA1 neurons.

\section{Results}

\section{Activation of group I mGluRs is required for the induction} of LTP by HFS in hippocampal CA1 neurons

As described in our previous study (Fujii et al. 1991), LTP was induced in the slope of the field excitatory postsynaptic potential (S-EPSP) and the amplitude of the population spike (A-PS) in hippocampal CA1 neurons by the delivery of HFS (a tetanus of 100 pulses at $100 \mathrm{~Hz}$ ) in standard perfusate. In Figure 1A, the top traces show sample wave forms and the main figure shows the summarized time-course of the change in the S-EPSP and A-PS in response to HFS. The mean LTP in the S-EPSP or A-PS measured 55-60 min after HFS was $150.6 \pm 4.7 \%(n=7)$ or $154.9 \pm 3.8 \%(n=7)$, respectively, of the pre-HFS levels. This induction by HFS of LTP in the S-EPSP and A-PS was blocked when $100 \mu \mathrm{M}$ S-4-carboxyphenylglycine (4CPG), a specific group I mGluR antagonist, was
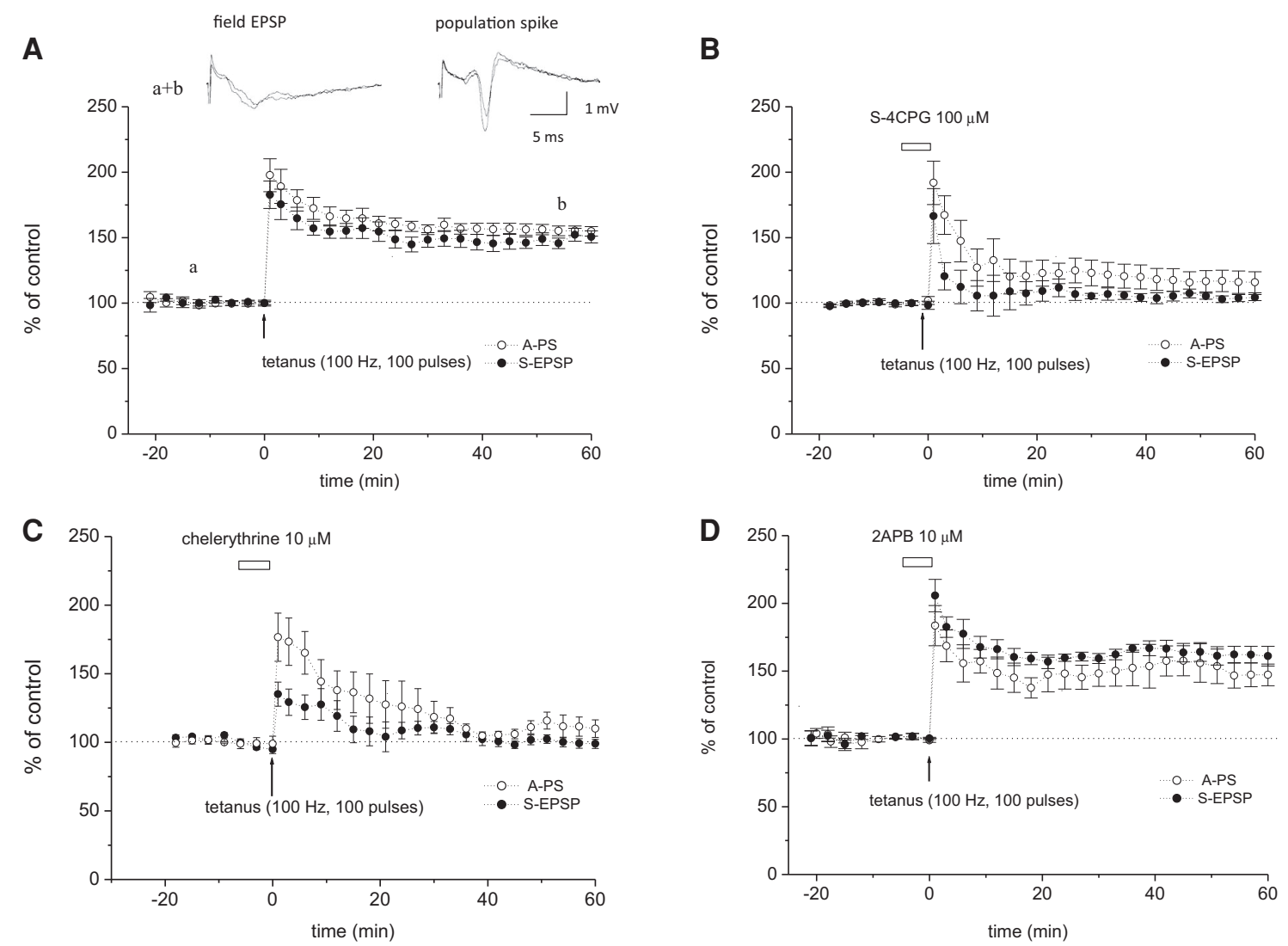

Figure 1. Effects of group I mGluRs or signaling molecules downstream from group I mGluRs on the induction of LTP in hippocampal CA1 neurons. (A) Sample waveforms and summarized time-course for the LTP in the S-EPSP or the A-PS induced by an HFS consisting of 100 pulses at $100 \mathrm{~Hz}(n=7)$. The sample waveforms were taken at the times indicated as $a$ and $b$ in the time-course figure. $(B-D)$ Summarized time-course for the change in the $S$-EPSP or the A-PS induced by HFS of 100 pulses at $100 \mathrm{~Hz}$ when $100 \mu \mathrm{M} \mathrm{S-4CPG}(B, n=8), 10 \mu \mathrm{M}$ chelerythrine $(C, n=5)$, or $10 \mu \mathrm{M} 2-\mathrm{APB}(D, n=6)$ was added for 5 min before and during HFS, as shown by the horizontal bars. Test synaptic inputs at $0.05 \mathrm{~Hz}$ were applied throughout the experiment. In these figures, the ordinate shows the A-PS or the S-EPSP expressed as a percentage of the averaged value measured during the 10 min before delivery of HFS. The symbols and bars represent the mean \pm SEM. 
applied to CA1 neuron synapses for the $5 \mathrm{~min}$ immediately before the start of, and during, HFS delivery (Fig. 1B); the mean S-EPSP or A-PS measured 55-60 min after HFS was $101.4 \pm 3.0 \%(n=8)$ or $119.3 \pm 8.3 \%(n=8)$, respectively, of the pre-HFS level, both values being significantly lower than the corresponding value in the absence of the inhibitor (Fig. 1A). Thus, in hippocampal CA1 neurons, induction of LTP was suppressed when activation of group I mGluRs was inhibited during the 5-min period before, and during, the delivery of HFS.

We then studied the effects of the activation of PKC or $\mathrm{IP}_{3} \mathrm{Rs}$, which act downstream from group I mGluRs in the signaling cascade, immediately before and/or during HFS by perfusing slices with $10 \mu \mathrm{M}$ chelerythrine (a PKC inhibitor) or $10 \mu \mathrm{M} 2$-APB (an inhibitor of $\mathrm{IP}_{3}$ Rs or store-operated calcium [SOC] channels) for $5 \mathrm{~min}$ before, and during, HFS. As shown in Figure 1C, application of $10 \mu \mathrm{M}$ chelerythrine $(n=5)$ resulted in failure of LTP induction in the field EPSP or PS; the mean S-EPSP or A-PS measured $55-60$ min after the HFS was $98.9 \pm 3.3 \%$ or $110 \pm 6.4 \%$, respectively, of the pre-HFS level, both values being significantly lower $(P<0.01)$ than the corresponding value in the absence of the inhibitor (Fig. 1A), indicating that activation of PKC during, and/or after, HFS is necessary for the induction of LTP in hippocampal CA1 neurons. In addition, as shown in Figure 1D, when the slices were perfused with $10 \mu \mathrm{M} 2$-APB for the same 5-min period $(n=6)$, LTP was induced in the S-EPSP and A-PS; the mean S-EPSP or A-PS measured 55-60 min after the HFS was $147.3 \pm$ $8.0 \%$ or $161.1 \pm 7.3 \%$, respectively, of the pre-HFS level, neither value being significantly different from the corresponding value in the absence of the inhibitor (Fig. 1A). Thus, in hippocampal CA1 neurons, induction of LTP is not suppressed when activation of $\mathrm{IP}_{3} \mathrm{Rs}$ or SOC channels is inhibited during, and/or after, delivery of HFS.

\section{Activation of group $1 \mathrm{mGluRs}$ prior to HFS prevents LTP induction}

As shown in Figure 2A, induction of LTP in the S-EPSP or A-PS was suppressed when $10 \mu \mathrm{M}$ DHPG, a specific group I mGluR agonist, was applied to the slices $(n=6)$ for the 5 -min period before, and during, application of HFS (DHPG-induced LTP suppression); the mean magnitude of the S-EPSP or A-PS measured 55-60 min after HFS was $102.7 \pm 4.0 \%$ or $113.3 \pm 10.5 \%$ of the pre-HFS level, both values being significantly lower $(P<0.01)$ than the corresponding value in the absence of the inhibitor (Fig. 1A), showing that activation of group I mGluRs is involved in the mechanism of LTP suppression in hippocampal CA1 neurons.

As shown in Figure 2B, application of $10 \mu \mathrm{M}$ chelerythrine at the same time as $10 \mu \mathrm{M}$ DHPG $(n=6)$ did not affect the DHPG-induced LTP suppression in the field EPSP or PS; the mean S-EPSP or A-PS measured 55-60 min after HFS was $99.1 \pm$ $5.8 \%$ or $94.5 \pm 3.1 \%$ of the pre-HFS level, both values being significantly lower $(P<0.01)$ than the corresponding value in the absence of inhibitor. This shows that PKC activation is not involved in the mechanism of DHPG-induced LTP suppression
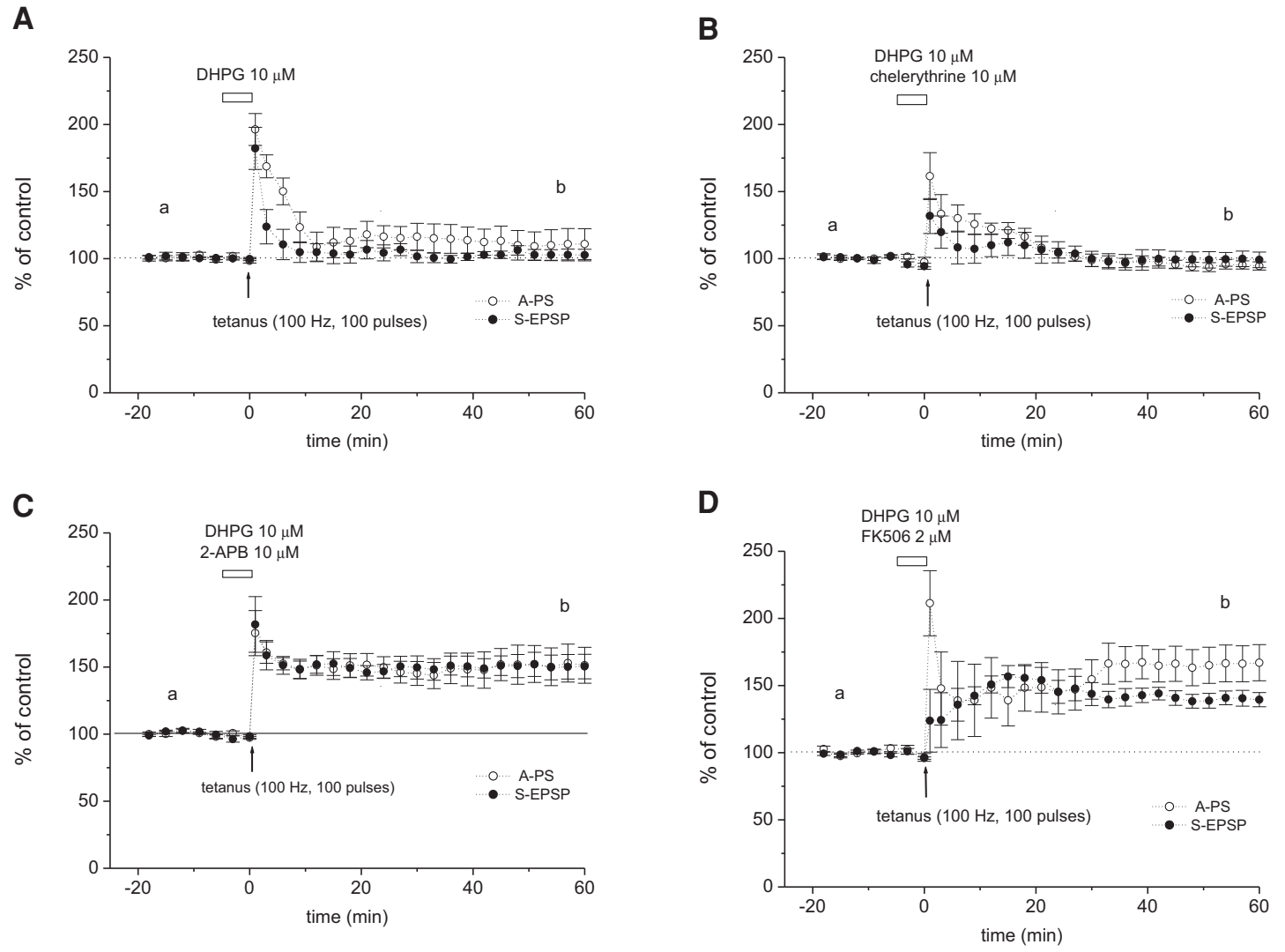

Figure 2. Preconditioning effect of $10 \mu \mathrm{M}$ DHPG on the induction of LTP at hippocampal CA1 synapses. (A) Summarized time-course for the LTP in the S-EPSP or the A-PS induced by an HFS consisting of 100 pulses at $100 \mathrm{~Hz}$ after application of $10 \mu \mathrm{M}$ DHPG for the 5 min before and during, HFS $(n=6)$. $(B-D)$ Summarized time-course for the change in the S-EPSP or the A-PS induced by an HFS of 100 pulses at $100 \mathrm{~Hz}$ after coapplication of $10 \mu \mathrm{M}$ DHPG and $10 \mu \mathrm{M}$ chelerythrine $(B, n=6)$, DHPG and $10 \mu \mathrm{M}$ 2-APB $(C, n=6)$, or DHPG and $2 \mu \mathrm{M}$ FK-506 $(D, n=6)$ for the same 5-min period. Test synaptic inputs at $0.05 \mathrm{~Hz}$ were applied throughout the experiment. PPS was also applied in the standard perfusate at the times indicated as a and $\mathrm{b}$ and the results are shown in Figure 3. 
in hippocampal CA1 neurons. However, as shown in Figure 2C, application of $10 \mu \mathrm{M} 2-\mathrm{APB}$ at the same time as $10 \mu \mathrm{M}$ DHPG $(n=6)$ blocked the DHPG-induced LTP suppression in the S-EPSP or PS; the mean LTP in the S-EPSP or A-PS was $150.4 \pm$ $9.1 \%$ or $151.3 \pm 13.4 \%$ of the pre-HFS level, neither value being significantly different from the corresponding value in the absence of inhibitors. We therefore conclude that activation of $\mathrm{IP}_{3} \mathrm{Rs}$ prior to HFS is involved in the mechanism of DHPGinduced LTP suppression in hippocampal CA1 neurons.

We hypothesized that $\mathrm{Ca}^{2+}$ efflux from internal stores prior to HFS triggers second messenger systems involved in DHPGinduced LTP suppression, including dephosphorylation of synaptic proteins at CA1 synapses. We therefore examined whether the $\mathrm{Ca}^{2+} /$ calmodulin-dependent protein phosphatase, calcineurin, was involved in DHPG-induced LTP suppression in hippocampal CA1 neurons. As shown in Figure 2D, application of $2 \mu \mathrm{M}$ FK-506 (a calcineurin inhibitor) at the same time as $10 \mu \mathrm{M}$ DHPG $(n=6)$ blocked the DHPG-induced LTP suppression in the S-EPSP or A-PS; the mean LTP in the S-EPSP or A-PS was $139.6 \pm 5.3 \%$ or $167.0 \pm 5.3 \%$ of the pre-HFS level, neither value being significantly different from the corresponding value in the absence of inhibitors, showing that activation of calcineurin is involved in the mechanism of DHPG-induced LTP suppression in CA1 neurons.
Since the effect of DHPG applied prior to HFS on the induction of LTP was suppressive, we examined whether inhibitory GABAergic transmission in the CA1 local inhibitory circuit or neurotransmitter release from CA1 presynaptic terminals was altered during the time course of DHPG-induced LTP suppression shown in Figure 2.

We first examined whether GABAergic synaptic transmission in the CA1 local inhibitory circuit was increased by applying paired-pulse stimulation (PPS) with a brief interval of $10 \mathrm{msec}$ for the period of 15-10 min before or 50-55 min after HFS at the points marked a and $b$ in Figure 2A-D. PPS at a 10-msec interval induces paired-pulse inhibition (PPI) of the responses, the amplitude of the second PS (Y in the inset of Fig. 3A) being smaller than that of the first ( $\mathrm{X}$ in the inset) and this PPS paradigm is commonly used to evaluate the efficacy of inhibitory synapses in the hippocampal CA1 region (Davies et al. 1991; Grunze et al. 1996; Freund and Busáki 1996). As shown in Figure 3A, PPI was not significantly changed after HFS in slices in which DHPG or DHPG plus chelerythrine was applied for the 5-min period before, and during, application of HFS, conditions that suppressed LTP induction (Fig. 2A,B). Moreover, PPI was also not significantly changed after HFS in slices in which DHPG and either 2-APB or FK506 was coapplied, conditions in which LTP was induced (Fig. 2C,D). Thus, inhibitory synaptic transmission in the CA1 local inhibitory

A

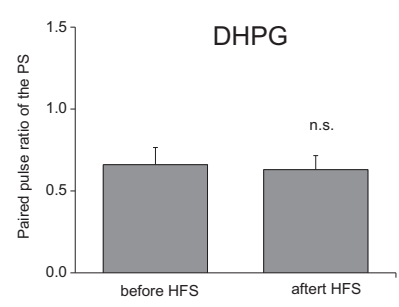

B

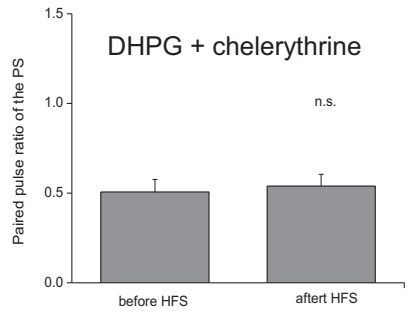

Paired pulse facilitation

(inter-pulse interval : $30 \mathrm{msec}$ )

\begin{abstract}
Paired pulse inhibition
(inter-pulse interval : $10 \mathrm{msec}$ )
\end{abstract}
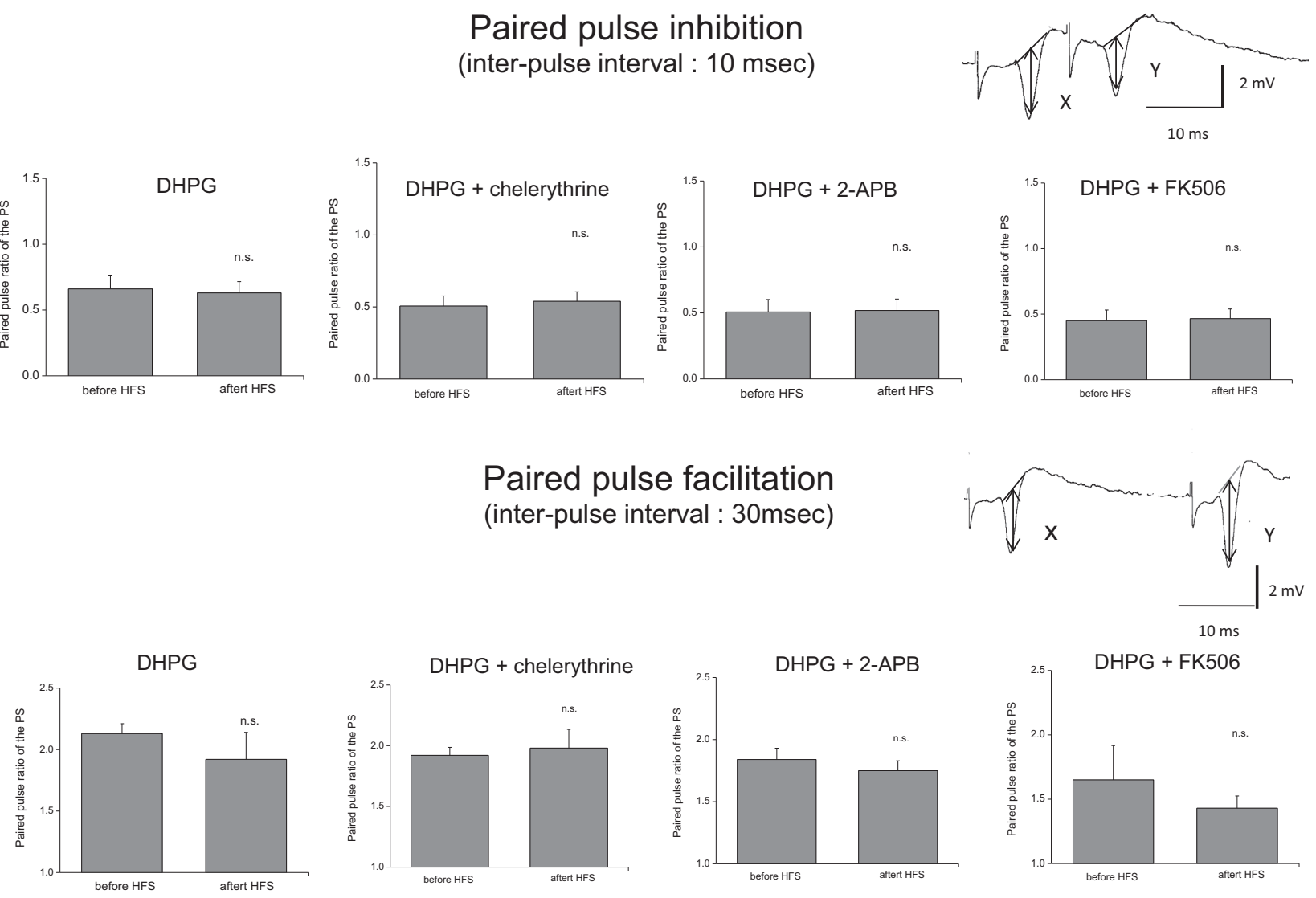

Figure 3. Changes after the HFS in the paired-pulse ratio in response to PPS. PPS at an interval of 10 (for PPI) or 30 msec (for PPF) was applied to the input pathway of the CA1 neurons at the points marked $a$ and $b$ in Figure $2 A-D$; the insets in Figure $3 A$ or $B$ illustrate the PPI induced by PPS at an interval of $10 \mathrm{msec}(A)$ or the PPF induced by PPS at an interval of $30 \mathrm{msec}(B)$, in which the values $X$ and $Y$ are the amplitudes of the PS induced by the first and second stimulus. The results shown are, left to right, those with application of $10 \mu \mathrm{M}$ DHPG (DHPG, $n=6$ ) or coapplication of $10 \mu \mathrm{M}$ DHPG with $10 \mu \mathrm{M}$ chelerythrine (DHPG + chelerythrine, $n=6), 10 \mu \mathrm{M}$ 2-APB (DHPG + 2-APB, $n=6$ ) or $2 \mu \mathrm{M}$ FK-506 (DHPG + FK506, $n=6)$ during the 5 min before and during HFS. The vertical axis represents the value for the A-PS induced by the second stimulus expressed as a ratio of that induced by the first stimulus $(\mathrm{Y} / \mathrm{X})$, while the horizontal axis indicates when PPS was applied. The symbols and bars represent the mean \pm SEM. n.s., no significant difference in the paired-pulse ratio after HFS. 
circuit was not significantly changed after HFS in slices in which LTP induction was suppressed and in slices in which LTP was induced. We therefore conclude that DHPG-induced LTP suppression in CA1 neurons is not due to enhancement of inhibitory synaptic transmission in the local inhibitory circuit in the CA1 region after delivery of HFS.

In the next step, to examine the location, i.e. presynaptic and/or postsynaptic, of the component(s) responsible for LTP suppression, we used PPS with an interval of $30 \mathrm{msec}$, which induces facilitation of the second response or "paired-pulse facilitation" (PPF, inset in Fig. 3B); This PPS paradigm is commonly used to evaluate the release of neurotransmitter from CA1 presynaptic terminals synapses (Manabe et al. 1993; Gerges et al. 2003). PPS was applied 5-10 min before or 50-55 min after HFS, respectively, at the points marked $a$ and $b$ in Figure $2 A-D$. As shown in Figure $3 \mathrm{~B}$, when DHPG was applied or DHPG and chelerythrine coapplied to the slices for the 5-min period before, and during, application of HFS, conditions under which failure of LTP induction was seen in CA1 neurons (Fig. 2A,B), PPF after HFS was not significantly changed. Moreover, when DHPG and either 2-APB or FK506 was coapplied to the slices for the same period prior to the delivery of HFS, conditions under which LTP was induced in CA1 neurons (Fig. 2C,D), PPF after HFS was again not significantly changed (Fig. 3A,B). Thus, neurotransmitter release from presynaptic terminals of CA1 synapses was not significantly changed after HFS in both slices in which LTP induction was suppressed and slices in which LTP was induced. We therefore conclude that failure of LTP suppression in hippocampal CA1 neurons is not induced simply by inhibiting the potentiation of presynaptic activity at CA1 synapses. Based on these results, we therefore sug- gest that $\mathrm{Ca}^{2+}$ efflux from internal stores in postsynaptic cells via $\mathrm{IP}_{3}$ Rs during, or after, HFS triggers the second messenger systems for LTP suppression in postsynaptic CA1 neurons.

\section{Effects of a preconditioning LFS on the HFS-induced LTP}

As shown in Figure 4A, in the absence of drugs, LTP induction in the field EPSP or PS was suppressed when an LFS of 1000 pulses at 1 $\mathrm{Hz}$ was applied to CA1 neuron synapses $60 \mathrm{~min}$ before HFS delivery (LFS-induced LTP suppression) $(n=6)$. The S-EPSP (left panel) or A-PS (right panel) measured 55-60 min after the LFS was, respectively, $93.6 \pm 3.3 \%$ or $92.8 \pm 9.0 \%$ of the pre-LFS value, neither value being significantly different from the pre-LFS value, and the S-EPSP or A-PS measured 55-60 min after HFS was, respectively, $96.5 \pm 6.3 \%$ or $108.8 \pm 11.6 \%$ of the pre-LFS value, neither value being significantly different from the pre-LFS value, and equal to $101.3 \pm 4.2 \%$ or $113.4 \pm 3.4 \%$ of the pre-HFS value (control in Table 1), both values being significantly lower than the corresponding value for the control LTP (Fig. 1A). Thus, an attempt to induce LTP 60 min after LFS of 1000 pulses at $1 \mathrm{~Hz}$ resulted only in short-term potentiation, while the LFS itself produced no significant change in the S-EPSP or A-PS.

As shown in Figure 4B, when the test synaptic stimulation at $0.05 \mathrm{~Hz}$ was halted for the 20-min period at 20-40 min after the end of LFS (no stimulation (1)), suppression of the HFS-induced LTP in the S-EPSP or A-PS was attenuated in the S-EPSP (filled triangles in the left panel of Fig. 4B) or A-PS (filled triangles in the right panel of Fig. 4B). Table 1 shows that the mean magnitudes of the S-EPSP and A-PS measured 55-60 min after LFS were not significantly different from the corresponding values for the control
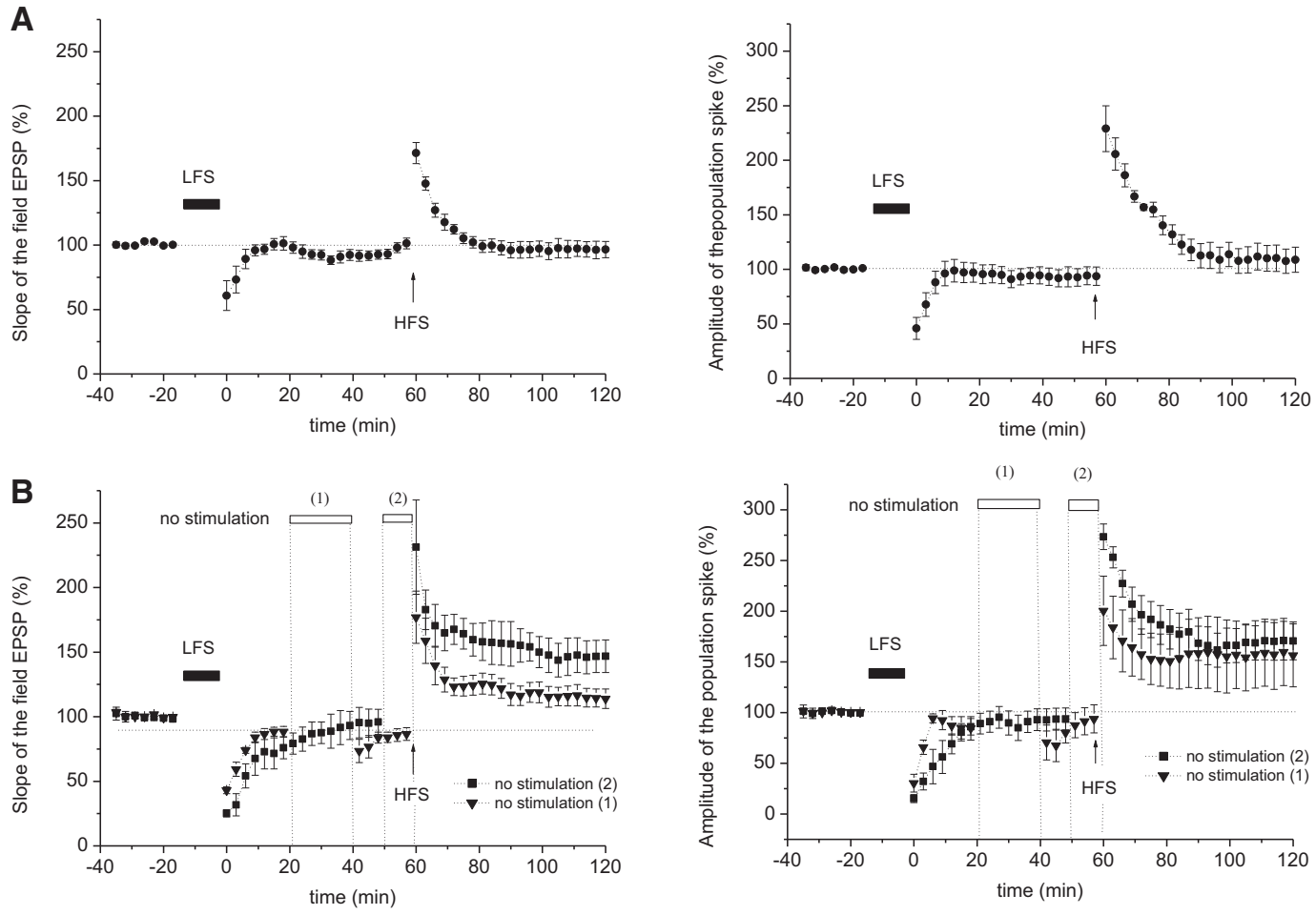

Figure 4. Effects of halting test stimulation at different times after LFS on LTP suppression. (A) Group data for LFS-induced LTP suppression in the S-EPSP (left panel) or the A-PS (right panel) in standard perfusate $(n=6)$. Test synaptic inputs at $0.05 \mathrm{~Hz}$ were applied throughout the experiment and a train of LFS of 1000 pulses at $1 \mathrm{~Hz}$ (black horizontal bar) or an HFS consisting of 100 pulses at $100 \mathrm{~Hz}$ (arrow) was applied where indicated. (B) Failure of LFS-induced LTP suppression in the S-EPSP (left panel) or the A-PS (right panel) when test synaptic input was halted (1) for the 20 min period at 20-40 min after the end of LFS ( $n=5$, filled triangles) or (2) for a 10-min period immediately before the delivery of HFS ( $n=5$, filled squares). A train of LFS of 1000 pulses at $1 \mathrm{~Hz}$ or consisting of 100 pulses at $100 \mathrm{~Hz}$ was applied where indicated by the lower horizontal bar or the arrow, respectively. Upper white bars represent the halt in test synaptic input. 
Table 1. Effects on LTP suppression of halting the test stimuli at different times after LFS

\begin{tabular}{|c|c|c|c|c|c|c|c|}
\hline \multirow[b]{2}{*}{ Stimuli halted } & \multirow[b]{2}{*}{$n$} & \multicolumn{2}{|c|}{$\begin{array}{l}\% \text { Change at } 55-60 \mathrm{~min} \text { or } \\
\text { at } 45-50 \mathrm{~min} \text { after LFS }\end{array}$} & \multicolumn{2}{|c|}{$\begin{array}{c}\% \text { Change at } 55-60 \mathrm{~min} \text { after } \\
\text { HFS }\end{array}$} & \multicolumn{2}{|c|}{$\begin{array}{l}\text { LTP as a percentage of the } \\
\text { pre-HFS value }\end{array}$} \\
\hline & & S-EPSP & A-PS & S-EPSP & A-PS & S-EPSP & A-PS \\
\hline Control & 6 & $93.6 \pm 3.3$ & $92.8 \pm 9.0$ & $96.5 \pm 6.3$ & $108.8 \pm 11.6$ & $101.3 \pm 4.2$ & $113.4 \pm 3.4$ \\
\hline 20-40 min after LFS & 5 & $\begin{array}{l}86.8 \pm 5.0 \\
960+9.7\end{array}$ & $93.9 \pm 13.9$ & $\begin{array}{l}113.9 \pm 7.1 \\
1468+126^{*}\end{array}$ & $165.0 \pm 14.5^{* *}$ & $\begin{array}{l}132.0 \pm 7.0^{* *} \\
1561 \pm 114^{* *}\end{array}$ & $\begin{array}{l}165.0 \pm 14.5^{* *} \\
185.9+166^{* *}\end{array}$ \\
\hline $50-60 \mathrm{~min}$ after LFS & 5 & $96.0 \pm 9.7$ & $93.8 \pm 10.9$ & $146.8 \pm 12.6^{*}$ & $170.7 \pm 18.6^{*}$ & $156.1 \pm 11.4^{* *}$ & \\
\hline
\end{tabular}

Top and center row: mean percentage change in the S-EPSP and A-PS measured 55-60 min after LFS or 55-60 min after HFS and in the LTP in the S-EPSP and A-PS measured 55-60 min after HFS when the test stimuli were not halted (control) or were halted during the 20-min period from 20-40 min after the end of LFS. Bottom row: mean percentage change in the S-EPSP and A-PS measured $45-50$ min after LFS or 55-60 min after HFS and in the LTP in the S-EPSP and A-PS measured 55-60 min after HFS when the test stimuli were halted during the 10-min period from 50-60 min after the end of LFS. Values are the mean \pm SEM. $n$, number of experiments. $\left(^{*}\right) P<0.05,\left(^{* *}\right) P<0.01$ (two-tailed Student's $t$-test) compared with the value for the LFS-induced suppression of the HFS-induced LTP when the test stimuli were not halted after LFS (control).

suppression of LTP (Fig. 4A). The mean magnitude of the S-EPSP measured 55-60 min after HFS was also not significantly different from the corresponding value for the control suppression of LTP, whereas the A-PS and the LTP of the S-EPSP and A-PS measured 55-60 min after HFS were significantly higher than the corresponding values for the control LTP. As also shown in Figure 4B, when the test synaptic stimulation at $0.05 \mathrm{~Hz}$ was halted for the 10-min period from 50-60 min after the end of LFS (i.e., the 10 -min period immediately before HFS delivery; no stimulation (2)), suppression of the HFS-induced LTP in the S-EPSP (left panel) or A-PS (right panel) was blocked. As shown in Table 1, the mean S-EPSP or A-PS, which, in this specific case, was measured 45-50 min after LFS, was not significantly different from the corresponding value for the control LTP suppression (Fig. 4A), whereas the mean S-EPSP and A-PS measured 55-60 min after HFS and the LTP of the S-EPSP or A-PS measured 55-60 min after HFS were all significantly higher than the corresponding values for the control LTP. These results suggest that delivery of LFS at $1 \mathrm{~Hz}$ has a preconditioning suppressive effect on the HFS-induced LTP at CA1 synapses and that this effect involves processes that are disrupted by halting the application of test synaptic stimuli prior to HFS.

In this study, we found that application of $10 \mu \mathrm{M}$ DHPG, a group I mGluR agonist, for the 5-min period immediately before, and during, HFS suppressed LTP induction in the S-EPSP or A-PS at naive CA1 neuron synapses (Fig. 2A) and that this effect was blocked by coapplication of $10 \mu \mathrm{M}$ 2-APB (Fig. 2C). These results suggest that a preconditioning LFS induces activation of group I mGluRs and/or $\mathrm{IP}_{3} \mathrm{Rs}$ in postsynaptic CA1 neurons and that this is maintained until at least immediately before delivery of HFS, leading to failure of LTP induction at CA1 synapses. It was therefore possible that the application of test electrical stimuli to Schaffer collaterals after the preconditioning LFS resulted in activation of group I mGluRs and/or $\mathrm{IP}_{3}$ Rs and induced LTP suppression when HFS was delivered $60 \mathrm{~min}$ after the end of the preconditioning LFS.

\section{Effects of mGluRs or NMDARs activated after the preconditioning LFS on the HFS-induced LTP suppression}

Since our previous study on the hippocampal CA1 region (Yamazaki et al. 2012b) showed that postsynaptic NMDAR activation occurs even at relatively low stimulation rates, i.e., 1 stimulus every $20 \mathrm{sec}(0.05 \mathrm{~Hz})$, it was possible that the application of test electrical stimuli after the preconditioning LFS-induced coactivation of mGluRs and NMDARs and that activation of both was required for suppression of LTP induction. We therefore examined whether mGluRs and/or NMDARs activated by test stimuli applied after LFS were involved in the suppression of HFS-induced LTP at CA1 synapses.
As shown in Figure 5A, when slices were perfused with $50 \mu \mathrm{M}$ D, L-2-amino-5-phosphonovalerate (AP5), a specific NMDAR inhibitor, $(n=5)$ or $500 \mu \mathrm{M}$ MCPG $(n=6)$ for the 20-min period of 20-40 min after the end of LFS in the presence of test synaptic inputs of Schaffer collaterals, the S-EPSP (left panel) and A-PS (right panel) were reduced below pre-perfusion levels during drug perfusion and recovered to pre-perfusion levels immediately before the delivery of HFS. As shown in Table 2, the mean values for the S-EPSP and A-PS at 55-60 min after the end of LFS were not significantly different from the corresponding values measured at 55-60 min in the control LFS-induced LTP suppression (Fig. 4A). However, in both cases, delivery of HFS 60 min after the end of the preconditioning LFS-induced LTP in the S-EPSP or A-PS. As shown in Table 2, the mean S-EPSP and A-PS measured 55-60 min after the HFS and the LTP of the S-EPSP or A-PS measured 55-60 min after HFS were all significantly higher than the corresponding value in the control (control in Table 1). Thus, these results show that the application of test electrical stimuli after the preconditioning LFS induces coactivation of mGluRs and NMDARs and that activation of both is required for the suppression of subsequent LTP induction in hippocampal CA1 neurons. As shown in Figure 5B and Table 2, similar results were obtained when $100 \mu \mathrm{M} \mathrm{S}-4 \mathrm{CPG}(n=5)$ or $10 \mu \mathrm{M} 2$-APB $(n=5)$ was used, showing that the application of test electrical stimuli after the preconditioning LFS induces activation of group I mGluRs and/or $\mathrm{IP}_{3} \mathrm{Rs}$ and that the activation of both of these after the LFS is required for the suppression of subsequent LTP induction in hippocampal CA1 neurons.

Our preceding study on LFS-induced LTP suppression in hippocampal CA1 neurons (Yamazaki et al. 2015) showed that coactivation of NMDARs and $\mathrm{IP}_{3}$ Rs during a preconditioning LFS results in calcineurin activation, leading to suppression of subsequent LTP induction. Since coactivation of NMDARs and $\mathrm{IP}_{3} \mathrm{Rs}$ by test synaptic inputs was required for the suppression of subsequent LTP induction in hippocampal CA1 neurons not only during the preconditioning LFS, but also after LFS, it was possible that coactivation of both receptors due to test synaptic inputs resulted in calcineurin activation after LFS, leading to suppression of LTP induction. As shown in Figure $5 \mathrm{~B}$, when slices $(n=4)$ were perfused with $2 \mu \mathrm{M}$ FK506 for the 20-min period of 20-40 min after the end of LFS in the presence of test synaptic inputs of Schaffer collaterals, the S-EPSP (left panel) and A-PS (right panel) were reduced below pre-perfusion levels during drug perfusion and recovered to pre-perfusion levels immediately before the delivery of HFS. As shown in Table 2, the mean values for the S-EPSP and A-PS at 55-60 min after the end of LFS were not significantly different from the corresponding values measured at 55-60 min in the control LFS-induced LTP suppression (Fig. 4A). However, in these slices, delivery of HFS $60 \mathrm{~min}$ after the end of the preconditioning LFS-induced LTP in the S-EPSP or A-PS. Based on this 

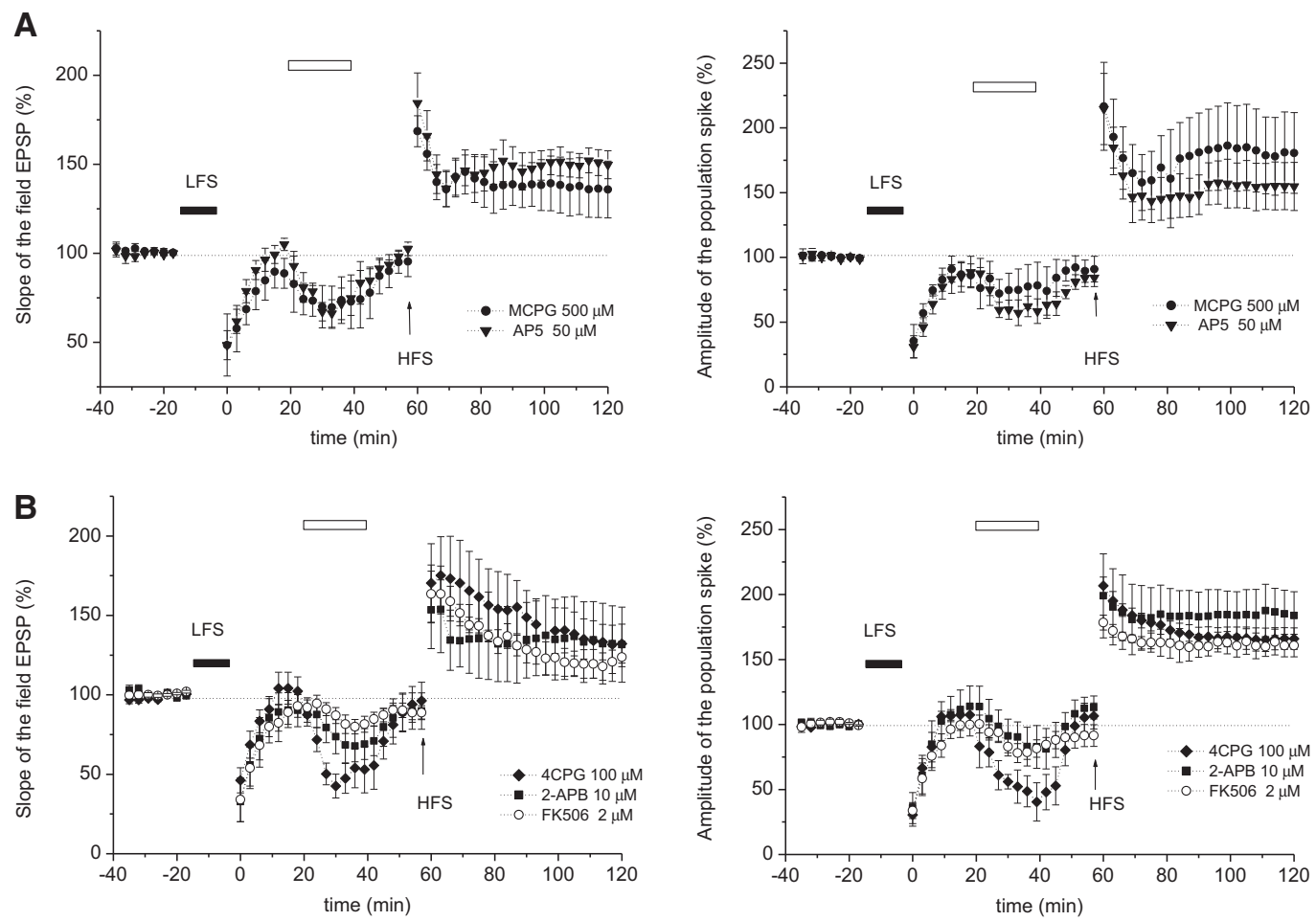

Figure 5. Effects on LTP suppression of NMDARs, mGluRs, group I mGluRs, or IP $\mathbb{P}_{3} R s$ activated after the preconditioning LFS. (A) Summarized results for the time-course of LTP suppression in the S-EPSP (left panel) or the A-PS (right panel) when $500 \mu \mathrm{M} \mathrm{RS-MCPG}(n=6$, filled diamonds) or $50 \mu \mathrm{M}$ AP5 $(n=$ 5 , filled triangles) was applied in the presence of test synaptic inputs during the 20 -min period from 20 to 40 min after the end of the LFS. (B) Summarized results for the time-course of LTP suppression in the S-EPSP (left panel) or the A-PS (right panel) when $100 \mu \mathrm{M} \mathrm{S-4CPG} \mathrm{(} n=5$, filled diamonds), $10 \mu \mathrm{M}$ 2-APB ( $n=5$, filled squares), or $2 \mu \mathrm{M} \mathrm{FK506} \mathrm{(} n=4$, empty circles) was applied in the presence of test synaptic input during the 20-min period from 20$40 \mathrm{~min}$ after the end of the LFS. The upper and lower horizontal bars represent LFS delivery and drug application, respectively, while the arrow indicates delivery of HFS.

result, we conclude that calcineurin, activated by test stimuli applied after LFS, is required for the LFS-induced suppression of LTP induction at CA1 synapses and that calcineurin activation that occurs during LFS is maintained after LFS by the test synaptic inputs applied to CA1 synapses.

\section{A preconditioning LFS activates group I mGluRs and suppresses LTP induction}

Next, we examined whether activation of group I mGluRs and/or $\mathrm{IP}_{3}$ Rs, maintained until at least immediately before the HFS, affected LTP induction. As shown in Figure 6, when the LFS was de- livered in the standard perfusate and $100 \mu \mathrm{M}$ S-4CPG was applied for the 5 min immediately before, and during HFS, LFS-induced suppression of LTP in the S-EPSP (left panel) and A-PS (right panel) was attenuated. As shown in Table 3, the mean S-EPSP and A-PS measured 55-60 min after LFS were not significantly different from the corresponding value for the control LTP suppression (Table 1). However, the mean S-EPSP and A-PS measured 55-60 min after the HFS and the LTP of the S-EPSP or A-PS measured 55-60 min after HFS were all significantly higher than the corresponding values in the control. When $10 \mu \mathrm{M} 2-\mathrm{APB}(n=5)$ was applied for the same 5-min period, failure of LTP suppression in the S-EPSP and A-PS was seen. As shown in Table 3, the mean

Table 2. Effect of application of NMDARs, mGluRs, or $I P_{3} R s$ antagonist or a calcineurin inhibitor for the period of 20-40 min after LFS on LTP suppression

\begin{tabular}{|c|c|c|c|c|c|c|c|}
\hline \multirow[b]{2}{*}{ Test reagent } & \multirow[b]{2}{*}{$n$} & \multicolumn{2}{|c|}{$\begin{array}{c}\% \text { Change at } 55-60 \mathrm{~min} \text { after } \\
\text { LFS }\end{array}$} & \multicolumn{2}{|c|}{$\begin{array}{c}\% \text { Change at } 55-60 \text { min after } \\
\text { HFS }\end{array}$} & \multicolumn{2}{|c|}{$\begin{array}{l}\text { LTP as a percentage of the } \\
\text { pre-HFS value }\end{array}$} \\
\hline & & S-EPSP & A-PS & S-EPSP & A-PS & S-EPSP & A-PS \\
\hline AP5 & 5 & $102.5 \pm 3.8$ & $84.3 \pm 6.8$ & $149.8 \pm 7.9^{* *}$ & $155.8 \pm 16.6^{*}$ & $148.5 \pm 3.1^{* *}$ & $185.4 \pm 16.8^{* *}$ \\
\hline MCPG & 6 & $95.4 \pm 8.0$ & $90.9 \pm 9.9$ & $135.8 \pm 16.0^{*}$ & $182.9 \pm 18.6^{* *}$ & $132.0 \pm 7.0^{* *}$ & $194.2 \pm 13.8^{* *}$ \\
\hline S-4CPG & 5 & $96.3 \pm 11.6$ & $106.6 \pm 10.0$ & $132.2 \pm 12.3^{*}$ & $166.0 \pm 8.3^{* *}$ & $139.9 \pm 8.5^{* *}$ & $151.5 \pm 16.5^{*}$ \\
\hline 2-APB & 5 & $89.9 \pm 11.4$ & $113.1 \pm 8.9$ & $131.6 \pm 23.7$ & $166.0 \pm 8.3^{* *}$ & $143.8 \pm 7.7^{* *}$ & $157.3 \pm 11.4^{*}$ \\
\hline FK506 & 4 & $90.6 \pm 6.0$ & $91.5 \pm 8.4$ & $121.4 \pm 3.5^{* *}$ & $147.3 \pm 8.2^{*}$ & $134.3 \pm 8.2^{* *}$ & $157.5 \pm 10.1^{* *}$ \\
\hline
\end{tabular}

Mean percentage change in the S-EPSP and A-PS measured 55-60 min after LFS or 55-60 min after HFS and in the LTP in the S-EPSP and A-PS measured 55-60 min after HFS when $50 \mu \mathrm{M}$ D, L-AP5, $500 \mu \mathrm{M}$ RS-MCPG, $100 \mu \mathrm{M} \mathrm{S-4CPG,} 10 \mu \mathrm{M}$ 2-APB, or $2 \mu \mathrm{M}$ FK506 was perfused from 20 to 40 min after the end of LFS. $n$, number of experiments. A significant difference compared with the corresponding value for the control LTP suppression induced in the absence of drugs (control in Table 1) is shown as $\left(^{*}\right) P<0.05$ or $\left(^{* *}\right) P<0.01$ (two-tailed Student's $t$-test). 

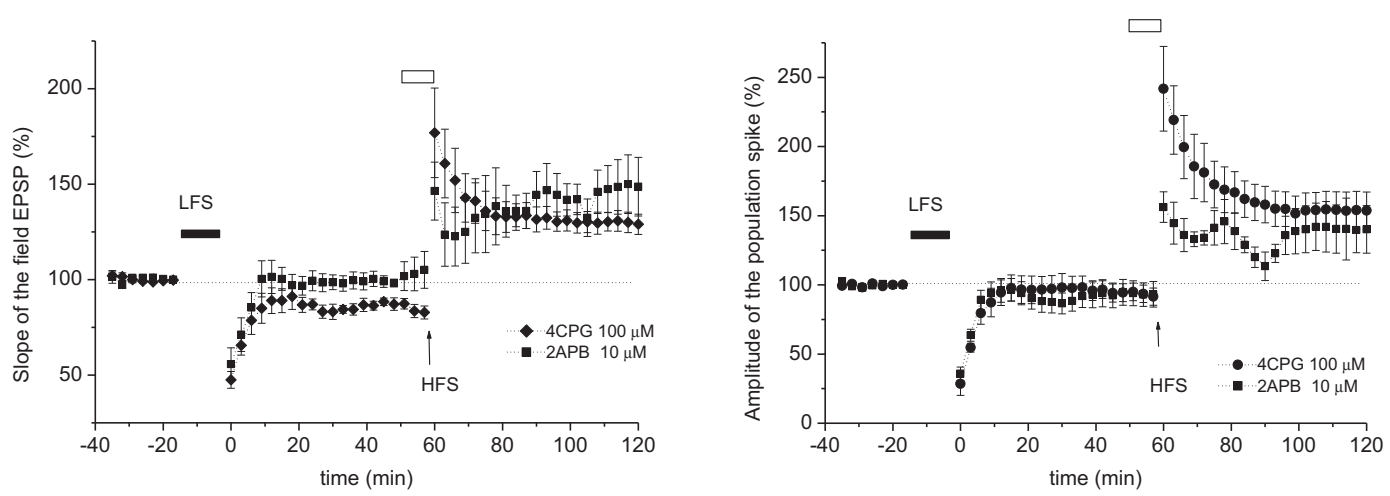

Figure 6. Involvement in LFS-induced LTP suppression of group I mGluRs and/or IP $\mathrm{P}_{3}$ s activated immediately before, or during, delivery of HFS. Summarized results for the time-course of LTP suppression in the S-EPSP (left panel) and the A-PS (right panel) when LFS was delivered in standard perfusate and $100 \mu \mathrm{M} \mathrm{S-4CPG} \mathrm{(} n=5$, filled diamonds or filled circles) or $10 \mu \mathrm{M} 2$-APB ( $n=5$, filled squares) was added for 5 min before, and during, HFS. The black and white horizontal bars indicate LFS and drug application, respectively, while the arrow indicates delivery of HFS.

$S$-EPSP and A-PS measured 55-60 min after LFS were not significantly different from the corresponding value for the control LTP suppression (Fig. 4A). However, the mean S-EPSP and A-PS measured 55-60 min after the HFS and the LTP of the S-EPSP or A-PS measured 55-60 min after HFS were all significantly higher than in the control (Table 1). These results show that the conditioning effect provided by the LFS is dependent on activation of $\mathrm{IP}_{3} \mathrm{Rs}$, which are downstream from group I mGluRs in the signaling cascade, and is attenuated by application of an antagonist of either of these receptors for 5 min before, and during, HFS. We suggest that the preconditioning LFS triggers postsynaptic cellular events necessary for induction of LTP suppression in CA1 neurons, including the activation of group I mGluRs and/or $\mathrm{IP}_{3} \mathrm{Rs}$ which is maintained at least till immediately before delivery of HFS to CA1 neurons.

\section{The suppressive effect of LFS on HPS-induced LTP cannot} be replaced by agonist activation of group I mGluRs

Since coactivation of NMDARs and $\mathrm{IP}_{3}$ Rs during a priming LFS results in activation of group I mGluRs after LFS, leading to suppression of subsequent LTP induction in hippocampal CA1 neurons (Yamazaki et al. 2015), we then examined whether chemical activation of group I mGluRs could replace the effects of the priming LFS on subsequent LTP induction. As shown in Figure 7A, LTP was induced in the S-EPSP or A-PS by HFS when no LFS was used, but $10 \mu \mathrm{M}$ DHPG was applied for the 10-min period from 25 to $35 \mathrm{~min}$ before application of HFS; the mean magnitude of the S-EPSP or A-PS measured 55-60 min after HFS was $135.7 \pm 7.0 \%(n=4)$ or $153.9 \pm 17.1 \%(n=4)$ of the pre-HFS level, both values being not significantly different from the corresponding value in the absence of DHPG (Fig. 1A), showing that, in the absence of an ap- plied LFS, activation of group I mGluRs for the 10 min period from 25 to 35 min before HFS application does not suppress LTP induction in hippocampal CA1 neurons.

When a priming LFS was applied in the presence of $10 \mu \mathrm{M}$ 2-APB to block $\mathrm{IP}_{3} \mathrm{Rs}$ and HFS was applied in standard perfusate, LFS failed to induce suppression of the HFS-induced LTP in the S-EPSP or A-PS $(n=6$, empty circles in Fig. 7B and DHPG $(-)$ in Table 4), as the magnitude of LTP in the S-EPSP or LTP in the A-PS, both measured 55-60 min after HFS, was still significantly higher $(P<0.01$ or 0.05$)$ than the corresponding values in the absence of 2-APB (Fig. 4A and control in Table 1). This result shows that activation of $\mathrm{IP}_{3}$ Rs during LFS is required for the blocking effects of the priming LFS on the subsequent HFS-induced LTP in hippocampal CA1 neurons.

We then examined whether the inhibitory effect of 2-APB applied during LFS on the suppressive effect of LFS on the HFS-induced LTP at CA1 synapses could be overcome by activation of group I mGluRs before HFS. When $10 \mu \mathrm{M} 2$-APB was applied during the preconditioning LFS and $10 \mu \mathrm{M}$ DHPG was applied in the presence of test stimuli during the 10-min period from 25 to $35 \mathrm{~min}$ after the end of LFS, subsequent application of HFS-induced LTP in the S-EPSP or A-PS $(n=4$, filled circles in Fig. 7B and DHPG (+) in Table 4), as the LTP in the S-EPSP and the LTP in the A-PS measured 55-60 min after HFS were both not significantly different from the corresponding values in the absence of DPHG (DHPG (-) in Table 4), but were significantly higher $(P<0.01$ or 0.05$)$ than the corresponding values for the control LFS-induced LTP suppression (control in Table 1). This result shows that application of $10 \mu \mathrm{M}$ DHPG to slices during the 10 -min period from 25 to $35 \mathrm{~min}$ after the end of LFS applied in the presence of 2 -APB did not replace the effects of the LFS in the suppression of subsequent LTP induction in CA1 neurons.

Table 3. Effect of application of a group I mGluR or IP ${ }_{3} R$ antagonist for the period of 55-60 min after LFS on LTP suppression

\begin{tabular}{|c|c|c|c|c|c|c|c|}
\hline \multirow[b]{2}{*}{ Test reagent } & \multirow[b]{2}{*}{$n$} & \multicolumn{2}{|c|}{$\begin{array}{c}\% \text { Change at } 55-60 \mathrm{~min} \\
\text { after LFS }\end{array}$} & \multicolumn{2}{|c|}{$\%$ Change at $55-60 \mathrm{~min}$ after HFS } & \multicolumn{2}{|c|}{$\begin{array}{l}\text { LTP as a percentage of the } \\
\text { pre-HFS value }\end{array}$} \\
\hline & & S-EPSP & A-PS & S-EPSP & A-PS & S-EPSP & A-PS \\
\hline $\begin{array}{l}\text { S-4CPG } \\
2-A P B\end{array}$ & $\begin{array}{l}5 \\
5\end{array}$ & $\begin{array}{r}85.8 \pm 3.4 \\
106.1 \pm 9.9\end{array}$ & $\begin{array}{l}96.0 \pm 6.3 \\
94.5 \pm 9.9\end{array}$ & $\begin{array}{l}129.0 \pm 5.4^{* *} \\
149.5 \pm 15.1^{* *}\end{array}$ & $\begin{array}{l}161.3 \pm 11.6^{*} \\
139.2 \pm 17.4\end{array}$ & $\begin{array}{l}151.5 \pm 9.0^{* *} \\
139.8 \pm 4.5^{* *}\end{array}$ & $\begin{array}{l}161.3 \pm 11.6^{* *} \\
148.1 \pm 6.0^{* *}\end{array}$ \\
\hline
\end{tabular}

Mean percentage change in the S-EPSP and A-PS measured 55-60 min after LFS or 55-60 min after HFS and in the LTP in the S-EPSP and A-PS measured 5560 min after HFS when $100 \mu \mathrm{M}$ S-4CPG or $10 \mu \mathrm{M} 2$-APB was perfused from 55 to 60 min after the end of LFS. $n$, number of experiments. A significant difference compared to the corresponding value for the control LTP suppression induced in the absence of drugs (control in Table 1$)$ is indicated as (*) $P<0.05$ or $(* *) P<0.01$ (two-tailed Student's t-test). 

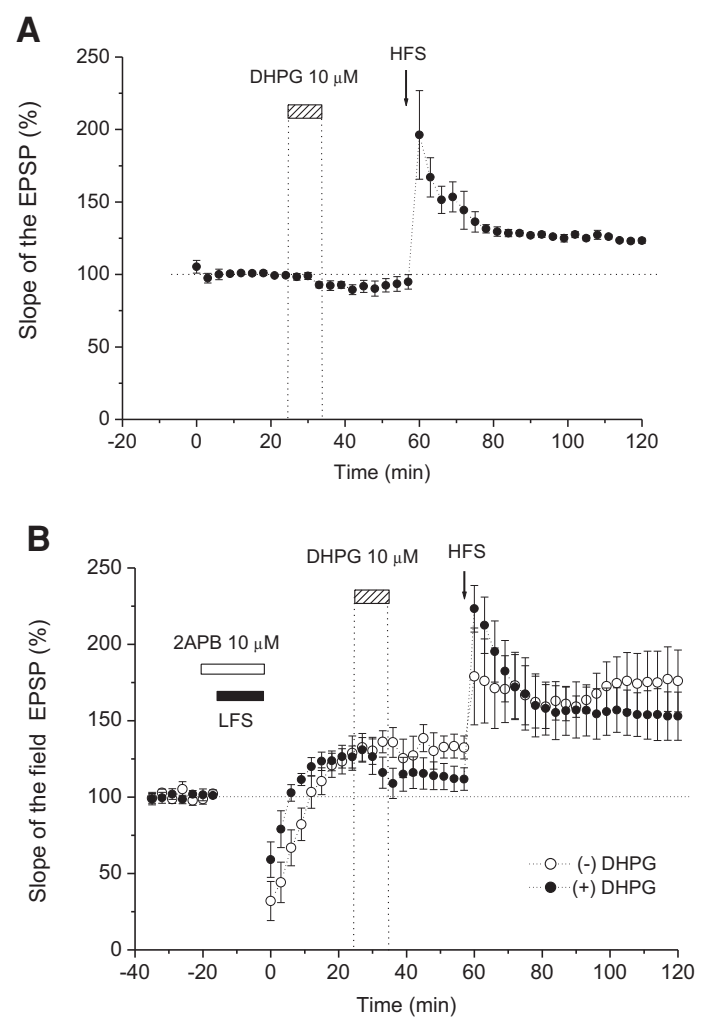
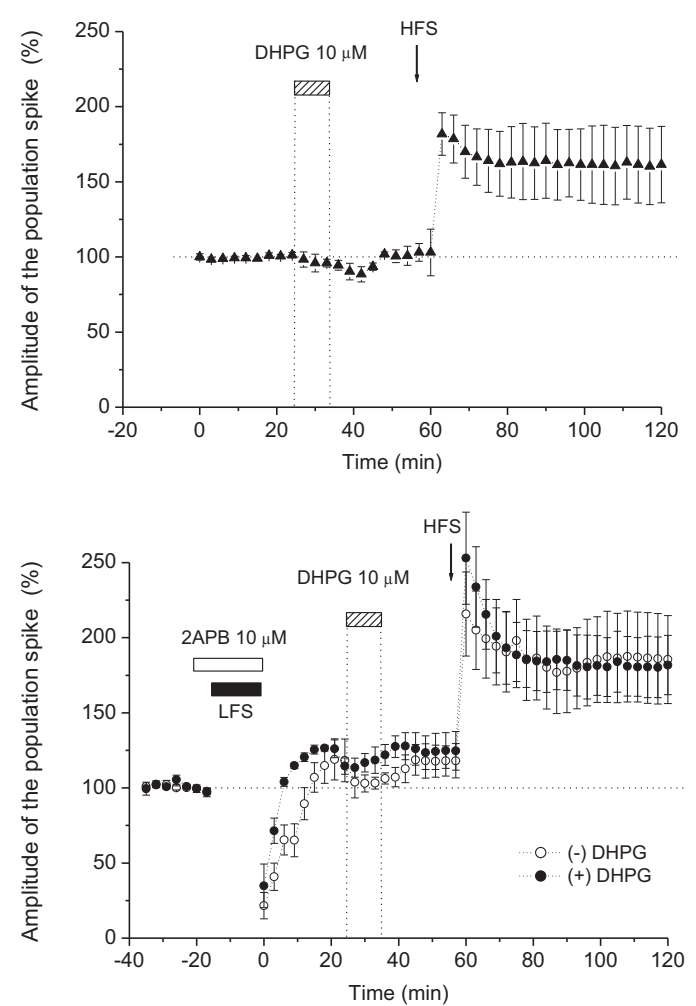

Figure 7. Application of $10 \mu \mathrm{M}$ DHPG after LFS cannot replace the effects of the priming LFS. (A) Summarized results for the time-course of LTP in the S-EPSP (left panel) and the A-PS (right panel) when $10 \mu \mathrm{M}$ DHPG was applied to the slices $(n=4)$ for the 10 min period from 25 to 35 min before application of HFS. (B) Summarized results for the time-course of the suppression of HFS-induced LTP in the S-EPSP (left panel) or A-PS (right panel) when 10 $\mu \mathrm{M}$ 2-APB was applied during the preconditioning LFS, but the test synaptic inputs were delivered in standard perfusate after the end of LFS ( $n=6$, empty circles), or when $10 \mu \mathrm{M}$ 2-APB was applied during the preconditioning LFS and $10 \mu \mathrm{M}$ DHPG applied during the 10-min period from 25to 35 min after the end of LFS ( $n=4$, filled circles). The black and white horizontal bars indicate LFS and 2-APB application, respectively, while the hatched horizontal bar and the arrow indicate DHPG application and delivery of HFS, respectively.

We therefore conclude that the LFS provides the conditioning effect for the subsequent block of LTP induction by HFS and that this is maintained by activation of group I mGluRs after LFS by the test synaptic inputs.

\section{Discussion}

Our results showed, that in hippocampal CA1 neurons, activation of group I mGluRs immediately before HFS delivery was required for both DHPG-induced LTP suppression (Figs. 2, 7A) and LFS-induced LTP suppression (Figs. 6, 7B), although the activation of these receptors was also involved in HFS-induced LTP induction itself (Fig. 1B). From the results shown in Figures 2 and 3, we conclude that the mechanism of DHPG-induced LTP suppression, which is postsynaptic, involves $\mathrm{IP}_{3} \mathrm{Rs}$ activated before and/or during, the HFS. We also showed that activation of $\mathrm{IP}_{3}$ Rs before delivery of the HFS was necessary for the induction of LFS-induced LTP suppression at CA1 synapses (Fig. 6). Given that the postsynaptic $\left[\mathrm{Ca}^{2+}\right]_{\mathrm{i}}$ increase at hippocampal CA1 synapses is caused by the activation of NMDARs and/or mGluRs (Pin and Duvoisin 1995; Otani and Connor 1998; Vytenis et al. 2001), and that activation of group I mGluRs before and/or during HFS is necessary for LTP suppression at CA1 synapses (Yamazaki et al. 2015), the results of our present study suggest that both $\mathrm{Ca}^{2+}$ efflux from internal stores through $\mathrm{IP}_{3} \mathrm{Rs}$ due to group I mGluR activation before,

Table 4. Effect of application of a group I mGluR agonist for the period of 25-35 min after LFS on inhibition of LTP suppression

\begin{tabular}{|c|c|c|c|c|c|c|c|}
\hline \multirow[b]{2}{*}{ Test reagent } & \multirow[b]{2}{*}{$n$} & \multicolumn{2}{|c|}{$\begin{array}{c}\% \text { Change at } 55-60 \mathrm{~min} \text { after } \\
\text { LFS }\end{array}$} & \multicolumn{2}{|c|}{$\%$ Change at $55-60 \mathrm{~min}$ after HFS } & \multicolumn{2}{|c|}{$\begin{array}{l}\text { LTP as a percentage of the } \\
\text { pre-HFS value }\end{array}$} \\
\hline & & S-EPSP & A-PS & S-EPSP & A-PS & S-EPSP & A-PS \\
\hline DHPG $(-)$ & 6 & $132.2 \pm 7.4^{* *}$ & $118.9 \pm 6.9^{*}$ & $176.0 \pm 20.7^{* *}$ & $181.8 \pm 19.7^{* *}$ & $136.6 \pm 6.1^{* *}$ & $152.9 \pm 16.3^{*}$ \\
\hline DHPG $(+)$ & 4 & $117.4 \pm 7.4^{*}$ & $123.8 \pm 13.0$ & $149.5 \pm 15.1^{* *}$ & $182.3 \pm 19.4^{* *}$ & $139.8 \pm 4.5^{* *}$ & $149.2 \pm 9.9^{* *}$ \\
\hline
\end{tabular}

Mean percentage change in the S-EPSP and A-PS measured 55-60 min after LFS or 55-60 min after HFS and in the LTP in the S-EPSP and A-PS measured 55-60 min after HFS when $10 \mu \mathrm{M}$ 2APB was perfused from 5 min before LFS to the end of LFS, then the test stimuli were applied from 25 to 35 min after the end of LFS in the presence of $10 \mu \mathrm{M}$ DHPG [DPHPG (+)] or standard perfusate [DHPG $(-)$ ]. $n$, number of experiments. A significant difference compared with the corresponding value for the control LTP suppression induced in the absence of drugs (control in Table 1) is indicated as $\left({ }^{*}\right) P<0.05$ or $(* *) P<0.01$ (twotailed Student's $t$-test). 
and/or during, HFS and $\mathrm{Ca}^{2+}$ influx through NMDAR/channels during HFS play an important role in LTP suppression in hippocampal CA1 neurons.

Two distinct $\mathrm{Ca}^{2+}$-releasing sites on the surface of the internal stores of the endoplasmic reticulum have been identified, these being the $\mathrm{IP}_{3} \mathrm{R}$, which is associated with an $\mathrm{IP}_{3}$-dependent $\mathrm{Ca}^{2+}$ store, and the ryanodine receptor (RyR), which is associated with SOC channels. Our previous studies on hippocampal CA1 neurons in $\mathrm{IP}_{3} \mathrm{R}$ 1-lacking mice demonstrated that the induction of LTP by a short tetanus of 10 pulses at $100 \mathrm{~Hz}$ or by a standard tetanus of 100 pulses at $100 \mathrm{~Hz}$ is facilitated in these mice (Fujii et al. 2000b; Nagase et al. 2003). Hippocampal CA1 neurons contain high levels of the type 3 RyR $\left(\mathrm{RyR}_{3}\right)$, but little type 1 or type 2 RyR (Furuichi et al. 1994). $\mathrm{RyR}_{3}$-deficient mice produced by gene targeting exhibit facilitation of LTP induction by a short tetanus at hippocampal CA1 synapses (Futatsugi et al. 1999), suggesting that calcium-induced calcium release, as a result of $\mathrm{Ca}^{2+}$ influx during/after tetanus, contributes to the suppression of LTP induction in hippocampal CA1 neurons. These results suggest that $\mathrm{Ca}^{2+}$ efflux through SOC channels and/or $\mathrm{IP}_{3} \mathrm{R} 1$ s during, and after, a short tetanus plays a role in suppressing synaptic potentiation in hippocampal CA1 neurons. Since these activity-dependent LTPs are generally believed to be triggered by the influx, during HFS, of $\mathrm{Ca}^{2+}$ into the postsynaptic neuron through channels coupled to NMDARs (Bliss and Collingridge 1993), we consider that, in these cells, an increase in the $\left[\mathrm{Ca}^{2+}\right]_{\mathrm{i}}$ due to $\mathrm{Ca}^{2+}$ efflux from internal stores and an increase due to $\mathrm{Ca}^{2+}$ influx through NMDARs during HFS may play opposite roles in LTP induction.

In hippocampal CA1 neurons, a standard tetanus given in the presence of 2-APB induced a similar LTP to that seen in the absence of 2-APB, both being maintained for at least $60 \mathrm{~min}$ (Fig. $1 \mathrm{~A}, \mathrm{D})$, while a short tetanus delivered in the presence of 2-APB was previously shown to induce a significantly larger LTP than that seen in the absence of 2-APB (Taufiq et al. 2005). LTP induction in hippocampal CA1 neurons requires sufficient depolarization of the postsynaptic membrane to activate NMDARs, and this depolarization depends on input activity (Collingridge et al. $1988 \mathrm{a}, \mathrm{b})$. Furthermore, an increase in the $\left[\mathrm{Ca}^{2+}\right]_{\mathrm{i}}$ through voltagegated calcium channels (VGCCs), which also depends on input activity, is thought to contribute to LTP induction (Ito et al. 1995). It is therefore possible that the LTP induction caused by the net $\mathrm{Ca}^{2+}$ influx through NMDAR/ $\mathrm{Ca}^{2+}$ channels or VGCCs overwhelms the LTP suppression caused by the net $\mathrm{Ca}^{2+}$ efflux from internal stores in postsynaptic CA1 neurons when CA1 synapses are stimulated by a standard tetanus. While the $\mathrm{Ca}^{2+}$ efflux through SOC channels and/or $\mathrm{IP}_{3} \mathrm{Rs}$ activated during a short or a standard HFS is the main cause of LTP suppression, Raymond and Redman (2002) observed that, in hippocampal CA1 neurons, inhibition of RyRs or $\mathrm{IP}_{3}$ Rs inhibits LTP induction by $\theta$-burst stimulation (TBS) consisting of one train or four trains of $10 \times 100 \mathrm{~Hz}$ bursts (five pulses per burst) with a 200 -msec inter-burst interval, and concluded that the large $\mathrm{Ca}^{2+}$ efflux from the two intracellular $\mathrm{Ca}^{2+}$ sources during TBS contributes to LTP induction.

In the biochemical steps following $\mathrm{Ca}^{2+}$ efflux from internal stores through $\mathrm{IP}_{3}$ Rs before and/or during HFS and $\mathrm{Ca}^{2+}$ influx through NMDAR/channels during HFS, the most likely candidates for stimulation by the postsynaptic $\left[\mathrm{Ca}^{2+}\right]_{\mathrm{i}}$ increase are protein phosphatase (PP) cascades, since dephosphorylation of serine 831 on the AMPAR GluA1 subunit, the major site phosphorylated by CaMKII (Lee et al. 2000), plays an essential role in the suppression of HFS-induced LTP in hippocampal CA1 neurons (Lisman 1994; Barria et al., 1997). In the PP cascades, there are two potential candidates that could be responsible for the process of LTP suppression in hippocampal CA1 neurons, one being PP1/ PP2A and the other PP2B (calcineurin), a $\mathrm{Ca}^{2+} /$ calmodulindependent PP that can indirectly increase PP1 activity by dephos- phorylating PP1 inhibitory proteins (Lisman 1994; Mulkey et al. 1994; Bear and Abraham 1996; Lee et al. 2000). In the present study, we showed that application of FK506, a calcineurin blocker, at the same time as DHPG inhibited the DHPG-induced LTP suppression in CA1 neurons (Fig. 2D). The shift from induction of LTP to suppression of LTP induction seen after either application of DHPG or delivery of $1 \mathrm{~Hz}$ LFS to CA1 synapses may be due to an increase in calcineurin activity in the dendrites of postsynaptic CA1 neurons following HFS of 100 pulses at $100 \mathrm{~Hz}$.

Mayford et al. (1995) reported that LTP induction following 5 $\mathrm{Hz}$ LFS is converted into LTD formation when levels of CaMKII autophosphorylated at threonine 286 are increased in hippocampal CA1 neurons. Since the affinity of CaMKII for the $\mathrm{Ca}^{2+} / \mathrm{cal}-$ modulin complex increases 1000 -fold after autophosphorylation of threonine 286 of the CaMKII $\alpha$-subunit (Meyer et al. 1992), Mayford et al. (1995) suggested that levels of the $\mathrm{Ca}^{2+} /$ calmodulin complex, which is sequestrated by the autophosphorylated CaMKII formed by LFS, are reduced to a point at which calcineurin is activated in the dendritic spines, resulting in a reduction of potentiation of synaptic transmission in hippocampal CA1 neurons. In our previous study (Taufiq et al. 2005), we found that delivery of HFS of 10 pulses at $100 \mathrm{~Hz}$ to CA1 synapses, which, by itself, does not induce NMDAR-dependent LTP in hippocampal CA1 neurons, induces LTP at CA1 synapses when combined with application of an mGluR or $\mathrm{IP}_{3} \mathrm{R}$ antagonist during HFS. In the present study, we showed that activation of group I mGluRs and/or $\mathrm{IP}_{3} \mathrm{Rs}$ before delivery of HFS was necessary for the induction of DHPG-induced LTP suppression (Fig. 2B,C). The shift from induction of LTP to suppression of LTP induction seen after application of DHPG may be due to a reduction in levels of $\mathrm{Ca}^{2+} /$ calmodulin complex formed following the postsynaptic $\left[\mathrm{Ca}^{2+}\right]_{\mathrm{i}}$ increase caused by the coactivation of NMDARs and group I mGluRs during HFS in the dendrites of postsynaptic CA1 neurons.

The results in Figs. 2A and 6 show that activation of group I mGluRs immediately before and/or during HFS and activation of NMDAR/channels during HFS play an important role in both DHPG-induced and LFS-induced LTP suppression in hippocampal CA1 neurons. Cohen et al. (1998) showed that application of 20 $\mu \mathrm{M}$ DHPG for the 10-min period of 30-20 min before the delivery of a tetanus consisting of a 500-msec train at $100 \mathrm{~Hz}$ caused a transient synaptic depression, but a significant enhancement of LTP induction in hippocampal CA1 neurons. In the present study, LTP was induced in the S-EPSP or A-PS when $10 \mu \mathrm{M}$ DHPG was applied for the 10-min period from 25 to 35 min before application of a tetanus of 100 pulses at $100 \mathrm{~Hz}$ (Fig. 7A). These results suggest that the time between group I mGluR activation and HFS determines whether LTP induction is facilitated or suppressed in hippocampal CA1 neurons.

$\mathrm{IP}_{3} \mathrm{R}$ binding protein released with $\mathrm{IP}_{3}$ (IRBIT), originally identified as a molecule that interacts with $\mathrm{IP}_{3} \mathrm{Rs}$ (Ando et al. 2003), binds to $\mathrm{IP}_{3} \mathrm{Rs}$ and suppresses $I \mathrm{IP}_{3} \mathrm{R}$ activity by blocking access of $\mathrm{IP}_{3}$ to $\mathrm{IP}_{3} \mathrm{R}$ by competing with $\mathrm{IP}_{3}$ for the common binding site on $\mathrm{IP}_{3} \mathrm{Rs}$ (Ando et al. 2006). Recently, Kawaai et al. (2015) identified CaMKII $\alpha$ as an IRBIT-interacting molecule in the central nervous system and showed that IRBIT binds to CaMKII $\alpha$ and suppresses its kinase activity by inhibiting the binding of the $\mathrm{Ca}^{2+} /$ calmodulin complex to the regulatory domain of CaMKII $\alpha$. Angiotensin II (ANG II stimulates renal tubular reabsorption of $\mathrm{NaCl}$ by targeting $\mathrm{Na}^{+} / \mathrm{H}^{+}$exchanger type 3 (NHE3) and IRBIT is involved in the ANG II-induced activation of NHE3 via a $\mathrm{Ca}^{2+} / \mathrm{CaMKII-dependent} \mathrm{pathway} \mathrm{(He} \mathrm{et} \mathrm{al.} \mathrm{2010).} \mathrm{ANG} \mathrm{II}$ increases binding of IRBIT to NHE3 at $5 \mathrm{~min}$, but becomes dissociated by $45 \mathrm{~min}$, and at least $15 \mathrm{~min}$ of ANG II treatment is required for an increase in NHE3 activity and NHE3 surface expression (He et al. 2010). Since LFS-induced LTP suppression in CA1 neurons is significantly attenuated when the interval 
between LFS and HFS is 20 or 100 min (Fujii et al. 1996), we think it possible that IRBIT released during and/or after the preconditioning LFS suppresses CaMKII $\alpha$ kinase activity in the dendritic cytoplasm of postsynaptic CA1 neurons during the 40-min period from 20 to $60 \mathrm{~min}$ after the end of the preconditioning LFS.

In the present study, the results shown in Figure 4 suggest that the presence or absence of CA1 synaptic inputs at $0.05 \mathrm{~Hz}$ after the preconditioning LFS determines whether or not the subsequent LTP induction is suppressed. Previous studies on the hippocampal CA1 region have shown that postsynaptic NMDAR activation occurs when test stimuli are given at a frequency as low as $0.05 \mathrm{~Hz}$ (Yang 2000; Yamazaki et al. 2012b). In the present study, halting the $0.05-\mathrm{Hz}$ test electrical stimulation of CA1 neurons during the 20-min period from 20 to $40 \mathrm{~min}$ after the end of the preconditioning LFS significantly attenuated the effects of the LFS on subsequent LTP induction (Fig. 4B). Since the effect of halting the electrical stimulation from 20 to $40 \mathrm{~min}$ after the end of the preconditioning LFS could be replaced by perfusion with $50 \mu \mathrm{M}$ AP5, $10 \mu \mathrm{M} 2 \mathrm{APB}$, or $2 \mu \mathrm{M}$ FK506 (Figs. 4B, 5A,B), it is possible that postsynaptic NMDARs/ channels activated by test synaptic inputs can cooperate with $\mathrm{IP}_{3} \mathrm{Rs}$ in triggering intracellular second messenger systems, including activation of calcineurin, to produce LTP suppression in CA1 neurons. In hippocampal CA1 neurons, the postsynaptic $\left[\mathrm{Ca}^{2+}\right]_{\mathrm{i}}$ increase during test stimulation due to both $\mathrm{Ca}^{2+}$ efflux from internal stores through $\mathrm{IP}_{3} \mathrm{Rs}$ and $\mathrm{Ca}^{2+}$ influx through NMDAR/channels may stimulate PP cascades to suppress LTP induction (Bliss and Collingridge 1993; Lismann 1994; Baumgärtel and Mansuy 2012) when IRBIT binds to CaMKII $\alpha$ and inhibits CaMKII $\alpha$ kinase activity during a certain period after the preconditioning LFS.

We suggest that the postsynaptic cellular events for the suppression of the HFS-induced LTP that are triggered by the preconditioning LFS involves sustained activation of group I mGluRs by the test synaptic input that increases $\mathrm{IP}_{3}$ and IRBIT levels in the cytoplasm of postsynaptic dendritic spines of CA1 neurons. As $\mathrm{Ca}^{2+}$ influx through NMDAR/channels during a tetanus of 100 pulses at $100 \mathrm{~Hz}$ induces $\mathrm{Ca}^{2+}$-induced $\mathrm{Ca}^{2+}$ release from intracellular stores in the dendrites of postsynaptic CA1 neurons (Alford et al. 1993), the activation of NMDARs by HFS will contribute to the increase in the dendritic $\left[\mathrm{Ca}^{2+}\right]_{\mathrm{i}}$ in postsynaptic CA1 neurons. In the presence of IRBIT, which inhibits CaMKII $\alpha$ kinase activity, HFS increases $\mathrm{Ca}^{2+} /$ calmodulin levels and activates calcineurin in the dendritic cytoplasm of the postsynaptic CA1 neurons, leading to failure of LTP induction. We therefore conclude that sustained activation of group I mGluRs and/or $\mathrm{IP}_{3}$ Rs after LFS preconditioning is essential for the LFS-induced LTP suppression in CA1 neurons.

\section{Materials and Methods}

\section{Slice preparation}

The animals used were maintained and handled following the guidelines of the Animal Care and Use Committee of the Yamagata University School of Medicine. Male Hartley guinea pigs (3- to 6-wk-old, Funabashi Farm Co., Tokyo, Japan) were decapitated and the hippocampi rapidly removed and cut into $500-\mu \mathrm{m}$ thick transverse slices using a rotary slicer (Dosaka DK-7700, Kyoto, Japan). The slices were preincubated for a minimum of $1 \mathrm{~h}$ at $30^{\circ} \mathrm{C}$ in a $95 \% \mathrm{O}_{2} / 5 \% \mathrm{CO}_{2}$ atmosphere in standard perfusion solution $\left[(\mathrm{mM}) \mathrm{NaCl}, 124 ; \mathrm{KCl}, 5.0 ; \mathrm{NaH}_{2} \mathrm{PO}_{4}, 1.25\right.$; $\mathrm{MgSO}_{4}, 2.0 ; \mathrm{CaCl}_{2}, 2.5 ; \mathrm{NaHCO}_{3}, 22.0$; and D-glucose, 10.0] before being placed in a $1 \mathrm{~mL}$ recording chamber and completely submerged in standard solution and perfused continuously at a rate of $2-3 \mathrm{~mL} / \mathrm{min}$, the temperature in the recording chamber being maintained at $30^{\circ} \mathrm{C}$.

\section{Electrophysiology}

A bipolar stimulating electrode was placed in the stratum radiatum to stimulate the input pathways to the CA1 neurons. One recording electrode was positioned in the stratum radiatum and another in the pyramidal cell body layer of the CA1 region to record, respectively, the field EPSP and the PS, and a test stimulus was applied every $20 \mathrm{sec}$ with a pulse duration of $0.1 \mathrm{msec}$. The S-EPSP and A-PS were measured and plotted automatically. The experimental protocol used in this study was as follows. At the beginning of each experiment, the strength of the stimulus pulse was adjusted to elicit a field EPSP with an initial slope 40\%-60\% of maximal and was then fixed at this level, then, after checking the stability of the S-EPSP for more than $15 \mathrm{~min}$, a conditioning stimulus of tetanus or LFS was delivered to induce synaptic plasticity at CA1 neurons.

To induce LTP, HFS consisting of one train of 100 pulses at $100 \mathrm{~Hz}$ (tetanus) was used (Fig. 1A), while, to suppress the induction of LTP, LFS consisting of 1000 pulses at $1 \mathrm{~Hz}$ was applied 60 min before HFS (Fig. 4A). The mean value of the S-EPSP or the A-PS during the 10 min immediately before delivery of LFS or HFS was defined as the $100 \%$ level and other responses expressed as a mean percentage \pm SEM of this level. To evaluate the suppressive effects of the preconditioning LFS on LTP induced by subsequent HFS delivery, the mean value of the S-EPSP or the A-PS in the 5-min period before the delivery of HFS was defined as the $100 \%$ control level and the mean magnitude of LTP of the S-EPSP and A-PS measured at 55-60 min after the HFS. In the case when the test synaptic stimulation was halted for the 10-min period from 50-60 min after the end of LFS, the mean magnitude of the S-EPSP or A-PS measured at 45-50 min, rather than that at 55-60 min after LFS, was defined as the 100\% control level (Fig. 4B and bottom row of Table 1).

In PPS studies, PPS was applied at either 15-10 min before, or 50-55 min after, delivery of HFS to the input pathway of the CA1 neurons at an interval of 10 or $30 \mathrm{msec}$ in the standard perfusate to induce, respectively, PPI or PPF of the A-PS elicited by the second of the paired stimuli. In the PPS study, the PPI or PPF was expressed as the A-PS produced by the second pulse (Y) expressed as a ratio of that produced by the first pulse $(\mathrm{X})$ (see the inset in Fig. 3A,B).

Chelerythrine chloride (chelerythrine), (RS)- $\alpha$-methyl-4carboxylphenylglycine (MCPG), (RS)-3,5-dehydroxyphenylglycine (DHPG), and $S$-4-carboxyphenylglycine (4-CPG) were purchased from Tocris Cookson Ltd., while 2-aminoethoxydiphenyl borate (2-APB) and FK-506 were obtained from Sigma-Aldrich. These drugs were applied from $5 \mathrm{~min}$ before and throughout HFS stimulation. In addition, 2-APB or 4-CPG was applied from 55 to $60 \mathrm{~min}$ after the end of LFS (during the $5 \mathrm{~min}$ immediately before HFS). D,L-2-amino-5-phosphonovalerate (AP5) obtained from Sigma (St. Louis, Mo), MCPG, 4-APB, or 4-CPG was applied during a $20 \mathrm{~min}$ period from 20 to $40 \mathrm{~min}$ after the end of LFS. Results were analyzed for statistical significance using the twotailed Student's $t$-test, taking a $P$ value $<0.05$ as significant.

\section{Acknowledgments}

This work was supported by JSPS KAKENHI grants 24500434, 25117005 , and 25350986.

\section{References}

Alford S, Frenguelli BG, Schofield JG, Collingridge GL. 1993. Characterization of $\mathrm{Ca}^{2+}$ signals induced in hippocampal CA1 neurons by the synaptic activation of NMDA receptors. J Physiol 469: 693-716. Ando H, Mizutani A, Matsu-ura T, Mikoshiba K. 2003. IRBIT, a novel inositol 1,4,5-trisphosphate $\left(\mathrm{IP}_{3}\right)$ Receptor-binding protein, is released from the $\mathrm{IP}_{3}$ receptor upon $\mathrm{IP}_{3}$ binding to the receptor. J Biol Chem 278: 10602-10612.

Ando H, Mizutani A, Kiefer H, Tsuzurugi D, Michikawa T, Mikoshiba K. 2006. IRBIT suppresses IP3 receptor activity by competing with IP3 for the common binding site on the IP3 receptor. Mol Cell 22: 795-806.

Barria A, Muller D, Derkach V, Griffith LC, Soderling TR. 1997. Regulatory phosphorylation of AMPA-type glutamate receptors by CaM-KII during long-term potentiation. Science 276: 2042-2045. 
Bashir ZI, Bortolotto ZA, Davies CH, Berretta N, Irving AJ, Seal AJ, Henley JM, Jane DE, Watkins JC, Collingridge GL. 1993. Induction of LTP in the hippocampus needs synaptic activation of glutamate metabotropic receptors. Nature 363: $347-350$.

Baumgärtel K, Mansuy IM. 2012. Neural functions of calcineurin in synaptic plasticity and memory. Learn Mem 19: 375-384.

Bear MF, Abraham WC. 1996. Long-term synaptic depression. Annu Rev Neurosci 19: 437-462

Behnisch T, Reymann KG. 1993. Co-activation of metabotropic glutamate and N-methyl-D-aspartate receptors is involved in mechanisms of long-term potentiation maintenance in rat hippocampal CA1 neurons. Neuroscience 54: $37-47$.

Ben-Ari Y, Anikstzen L, Bregestovski P. 1992. Protein kinase C modulation of NMDA currents: an important link for LTP induction. Trends Neurosci 5: $333-339$.

Berridge MJ. 1993. Inositol trisphosphate and calcium signalling. Nature 361: $315-325$.

Bliss TVP, Collingridge GL. 1993. A synaptic model of memory: long-term potentiation in the hippocampus. Nature 361: 31-39.

Bootman MD, Collins TJ, Mackenzie L, Roderick HL, Berridge MJ, Peppiatt CM. 2002. 2-Aminoethoxydiphenyl borate (2-APB) is a reliable blocker of store-operated $\mathrm{Ca}^{2+}$ entry but an inconsistent inhibitor of InsP3-induced $\mathrm{Ca}^{2+}$ release. FASEB J 16: $1145-1150$.

Bortolotto ZA, Bashir ZI, Davies CH, Collingridge GL. 1994. A molecular switch activated by metabotropic glutamate receptors regulates induction of long-term potentiation. Nature 368: 740-743.

Cohen AS, Raymond CR, Abraham WC. 1998. Priming of long-term potentiation induced by activation of metabotropic glutamate receptors coupled to phospholipase C. Hippocampus 8: 160-170.

Collingridge GL, Herron CE, Lester RA. 1988a. Synaptic activation of $\mathrm{N}$-methyl-D-aspartate receptors in the Schaffer collateral-commissural pathway of rat hippocampus. J Physiol 399: 283-300.

Collingridge GL, Herron CE, Lester RA. 1988b. Frequency-dependent $\mathrm{N}$-methyl-D-aspartate receptor-mediated synaptic transmission in rat hippocampus. J Physiol 399: 283-300.

Davies CH, Davies SN, Collingridge GL. 1991. Paired-pulse depression of monosynaptic GABA-mediated inhibitory postsynaptic responses in rat hippocampus. J Physiol 424: 513-531.

Freund TF, Buzsáki G. 1996. Interneurons of the hippocampus. Hippocampus 6: $347-470$.

Fujii S, Saito K, Ito K-I, Miyakawa H, Kato H. 1991. Reversal of long-term potentiation (depotentiation) induced by tetanus stimulation of the input to CA1 neurons of guinea pig hippocampal slices. Brain Res 555: $112-122$.

Fujii S, Kuroda Y, Miura M, Furuse H, Sasaki H, Kaneko K, Ito K-I, Kato H. 1996. The long-term suppressive effect of prior activation of synaptic inputs by low-frequency stimulation on induction of long-term potentiation in CA1 neurons of guinea-pig hippocampal slices. Exp Brain Res 111: 305-312.

Fujii S, Kuroda Y, Ito K-I, Yoshioka M, Kaneko K, Yamazaki Y, Sasaki H, Kato H. 2000a. Endogenous adenosine regulates the effects of low-frequency stimulation on the induction of long-term potentiation in CA1 neurons of guinea pig hippocampal slices. Neurosci Lett 279: $121-124$.

Fujii S, Matsumoto M, Igarahsi K, Kato H, Mikoshiba K. 2000b. Synaptic plasticity in hippocampal CA1 neurons of mice lacking type 1 inositol-1,4,5-trisphoshate receptors. Learn Mem 7: 312-320.

Fujii S, Yamazaki Y, Kuroda Y, Mikoshiba K. 2010. Involvement of inositol-1,4,5- trisphosphate receptors in the bidirectional synaptic plasticity induced in hippocampal CA1 neurons by $1-10 \mathrm{~Hz}$ low-frequency stimulation. Neuroscience 168: 346-358.

Furuichi T, Yoshikawa S, Miyawaki A, Wada K, Maeda N, Mikoshiba K. 1989 Primary structure and functional expression of the inositol 1,4,5-trisphosphate-binding protein $\mathrm{P}_{400}$. Nature 342: 32-38.

Furuichi T, Furutama D, Hakamata Y, Nakai J, Takeshima H, Mikoshiba K. 1994. Multiple types of ryanodine receptor $/ \mathrm{Ca}^{2+}$ release channels are differentially expressed in rabbit brain. J Neurosci 14: 4794-4805.

Futatsugi A, Kato K, Ogura H, Li S-T, Nagata E, Kuwajima G, Tanaka K, Itohara G, Mikoshiba K. 1999. Facilitation of NMDAR-independent LTP and spatial learning in mutant mice lacking ryanodine receptor type 3. Neuron 24: 701-713.

Gerges NZ, Aleisa AM, Alkadhi KA. 2003. Impaired long-term potentiation in obese Zucker rats: Possible involvement of presynaptic mechanism. Neuroscience 120: 535-539.

Grunze HCR, Rainnie DG, Hasselmo ME, Barkai E, Heam EF, McCarley RW, Greene RW. 1996. NMDA-dependent modulation of CA1 local circuit inhibition. J Neurosci 16: 2034-2043.

He P, Klein J, Yun CC. 2010. Activation of $\mathrm{Na}^{+} / \mathrm{H}^{+}$exchanger NHE3 by angiotensin II is mediated by inositol 1,4,5-triphosphate ( $\left.\mathrm{IP}_{3}\right)$ receptor-binding protein released with $\mathrm{IP}_{3}$ (IRBIT) and $\mathrm{Ca}^{2+} /$ calmodulin-dependent protein kinase II. J Biol Chem 285: 27869-27878.
Hulme SR, Jones OD, Ireland DR, Abraham WC. 2012. Calcium-dependent but action potential-independent BCM-like metaplasticity in the hippocampus. J Neurosci 6785: 6785-6794.

Ito K-I, Miura M, Furuse H, Chen Z, Kato H, Yasutomi D, Inoue T, Mikoshiba K, Kimura T, Sakakibara S, et al. 1995. Voltage-gated $\mathrm{Ca}^{2+}$ channel blockers, $\omega$-Aga IV and $\mathrm{Ni}^{2+}$, suppress the induction of $\theta$-burst induced long-term potentiation in guinea pig hippocampal CA1 neurons. Neurosci Lett 183: 112-115.

Iwasaki H, Mori Y, Hara Y, Uchida K, Zhou H, Mikoshiba K. 2001. 2-Aminoethoxydiphenyl borate (2-APB) inhibits capacitative calcium entry independently of the function of inositol 1,4,5-trisphosphate receptors. Receptors Channels 7: 429-439.

Kawaai K, Mizutani A, Shoji H, Ogawa N, Ebisu E, Kuroda Y, Wakana S, Miyakawa T, Hisatsume C, Mikoshiba K. 2015. IRBIT regulates CaMKIIa activity and contributes catecholamine homeostasis through the TH phosphorylation. Proc Natl Acad Sci 112: 5515-5520.

Lee H-K, Barbarosie M, Kameyama K, Bear MF, Huganir R. 2000. Regulation of distinct AMPA receptor phosphorylation sites during bidirectional synaptic plasticity. Nature 405: 955-959.

Lisman J. 1994. The CaMkinase II hypothesis for the storage of synaptic memory. Trends Neurosci 17: 406-412.

Manabe T, Wyllie DJA, Perkel DJ, Nicoll RA. 1993. Modulation of synaptic transmission and long-term potentiation effects on paired-pulse facilitation and EPSC variance in the CA1 region of the hippocampus. J Neurophysiol 70: 1451-1459.

Maruyama T, Kanaji T, Nakade S, Kanno T, Mikoshiba K. 1997. 2APB, 2 -aminoethoxydiphenyl borate, a membrane penetrable modulator of Ins $(1,4,5) \mathrm{P}_{3}$-induced $\mathrm{Ca}^{2+}$ release. J Biochem 122: 498-505.

Matsumoto M, Nakagawa T, Inoue T, Nagata E, Tanaka K, Takano H, Minowa O, Kuno J, Sakakibara S, Yamada M, et al. 1996. Ataxia and epileptic seizures in mice lacking type 1 inositol 1,4,5-trisphosphate receptor. Nature 379: 168-171.

Mayford M, Wang J, Kandel E, O'Dell TJ. 1995. CaMKII regulates the frequency-response function of hippocampal synapses for the production of both LTD and LTP. Cell 81: 891-904.

Meyer T, Hanson PI, Stryer L, Schulman H. 1992. Calmodulin trapping by calcium-calmodulin-dependent protein kinase. Science 256: $1199-1202$

Mikoshiba K. 1993. Inositol 1,4,5-trisphosphate receptor. Trends Pharmacol Sci 14: 86-9.

Mocket B, Coussens C, Abraham WC. 2002. NMDA receptor-mediated metaplasticity during the induction of long-term depression by low-frequency stimulation. Eur J Neurosci 15: 1819-1826.

Mulkey RM, Endo S, Shenolikars S, Malenka RC. 1994. Involvement of a calcineurin/inhibitor-1 phosphatase cascade in hippocampal long-term depression. Nature 369: 486-488.

Nagase T, Ito K-I, Kato K, Kaneko K, Kohda K, Matsumoto M, Hoshino A, Inoue T, Fujii S, Kato H. 2003. Long-term potentiation and long-term depression in hippocampal CA1 neurons of mice lacking the IP3 type 1 receptor. Neuroscience 117: 821-830.

Nakanishi S. 1992. Molecular diversity of glutamate receptors and implication for brain function. Science 258: 597-603.

Nakanishi S, Maeda N, Mikoshiba K. 1991. Immunohistochemical localization of an inositol 1,4,5-trisphosphate receptor, P400, in neural tissue: studies in developing and adult mouse brain. J Neurosci 11: $2075-2086$.

Otani S, Connor JA. 1998. Requirement of rapid $\mathrm{Ca}^{2+}$ entry and synaptic activation of metabotropic glutamate receptors for the induction of long-term depression in adult rat hippocampus. J Physiol 511: $761-770$

Peppiatt CM, Collins TJ, Mackenzie L, Conway SJ, Holmes AB, Bootman MD, Berridge MJ, Seo JT, Roderick HL. 2003. 2-Aminoethoxydiphenyl borate (2-APB) antagonises inositol 1,4,5-trisphosphate-induced calcium release, inhibits calcium pumps and has a use-dependent and slowly reversible action on store-operated calcium entry channels. Cell Calcium 34: 97-108.

Pin J-P, Duvoisin R. 1995. The metabotropic glutamate receptors: structures and functions. Neuropharmacology 34: 1-26.

Raymond CR, Redman SJ. 2002. Different calcium sources are narrowly tuned to the inhibition of different form of LTP. J Neurophysiol 88: $249-255$

Taufiq AM, Fujii S, Yamazaki Y, Sasaki H, Kaneko K, Li J, Kato H, Mikoshiba K. 2005. Involvement of IP3 receptors in LTP and LTD induction in guinea pig hippocampal CA1 neurons. Learn Mem 12 $594-600$

Vytenis A, Skeberdis JL, Optiz T, Zheng X, Michael VL, Bennet R, Zukin S. 2001. mGluR1-mediated potentiation of NMDA receptors involves a rise in intracellular calcium and activation of protein kinase C. Neuropharmacology 40: 856-865.

Yamazaki Y, Fujii S, Goto J-I, Sugihara M, Fujiwara H, Kaneko K, Aihara T, Mikoshiba K. 2012a. Suppressive effect of preconditioning low-frequency stimulation on subsequent induction of long-term 
potentiation by high frequency stimulation in hippocampal CA3 neurons. Brain Res 1449: 15-23.

Yamazaki Y, Fujii S, Aihara T, Mikoshiba K. 2012b. Activation of inositol 1, 4, 5-trisphosphate receptors during preconditioning low-frequency stimulation leads to reversal of LTP in hippocampal CA1 neurons. Neuroscience 207: 1-11.

Yamazaki Y, Fujii S, Goto J-I, Fujiwara H, Mikoshiba K. 2015. Activation of inositol 1, 4, 5-trisphosphate receptors during preconditioning low-frequency stimulation suppresses subsequent induction of long-term potentiation in hippocampal CA1 neurons. Neuroscience 311: $195-206$.

Yang S-N. 2000. Ceramide-induced sustained depression of synaptic currents mediated by ionotropic glutamate receptors in the hippocampus: an essential role of postsynaptic protein phosphatases. Neuroscience 96: 253-258.

Yoshioka M, Yamazaki Y, Fujii S, Kato H, Mikoshiba K. 2010. Intracellular calcium ion dynamics involved in long-term potentiation in hippocampal CA1 neurons in mice lacking the IP3 type 1 receptor. Neurosci Res 67: 149-155.

Young JZ, Nguyen PV. 2005. Homosynaptic and heterosynaptic inhibition of synaptic tagging and capture of long-term potentiation by previous synaptic activity. J Neurosci 25: 7221-7231.

Received November 9, 2015; accepted in revised form February 25, 2016. 


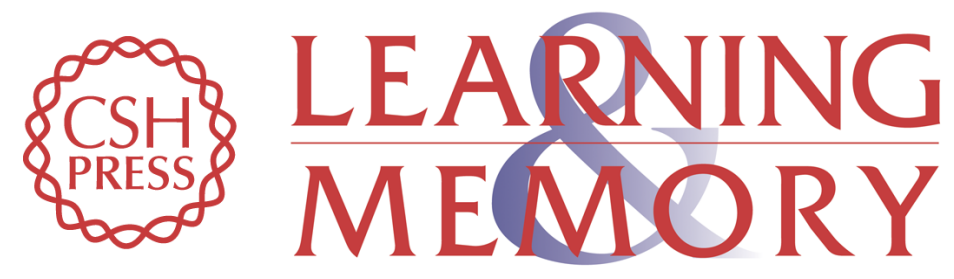

\section{Prior activation of inositol 1,4,5-trisphosphate receptors suppresses the subsequent induction of long-term potentiation in hippocampal CA1 neurons}

Satoshi Fujii, Yoshihiko Yamazaki, Jun-Ichi Goto, et al.

Learn. Mem. 2016, 23:

Access the most recent version at doi:10.1101/lm.041053.115

References This article cites 58 articles, 13 of which can be accessed free at: http://learnmem.cshlp.org/content/23/5/208.full.html\#ref-list-1

Creative This article is distributed exclusively by Cold Spring Harbor Laboratory Press for the Commons first 12 months after the full-issue publication date (see

License http://learnmem.cshlp.org/site/misc/terms.xhtml). After 12 months, it is available under a Creative Commons License (Attribution-NonCommercial 4.0 International), as described at http://creativecommons.org/licenses/by-nc/4.0/.

Email Alerting Receive free email alerts when new articles cite this article - sign up in the box at the Service top right corner of the article or click here. 